\title{
Evaluation of Postsurgical Dentofacial Deformities in Children Operated for Correction of Cleft Lip and Palate-A Cross-sectional Study
}

\author{
Chrishantha Joybell ${ }^{1}$, Ramesh Krishnan ${ }^{2}$, Suresh Kumar ${ }^{3}$
}

\begin{abstract}
Aim: The aim of this study is to evaluate the various dentofacial deformities in children who were surgically managed for cleft lip and palate (CLP). Materials and methods: The study was carried out in 100 surgically managed cleft lip palate children between the ages of 4 years and 15 years. After eliciting a detailed history, a thorough intraoral and extraoral examination was done and details were recorded in a printed proforma with photographs.

Design: Cross-sectional study.

Statistical analysis used: All the data were analyzed using SPSS 11.5 software for evaluation using the Chi-square test.

Results: A wide range of surgical, dental, and functional problems among the surgically managed CLP patients were seen.

Conclusion: The timing of direct lip repair showed a significant influence on the severity of dentofacial deformities. Lip repair before the age of 1 increases the severity of the deformity.

Keywords: Cleft lip, Cleft palate, Cleft lip and palate.

International Journal of Clinical Pediatric Dentistry (2019): 10.5005/jp-journals-10005-1613
\end{abstract}

\section{INTRODUCTION}

"What lies behind us and what lies before us are tiny matters compared to what lies within us"-Ralph Waldo Emerson

Every new smile on the face of a cleft lip palate child brings us closer to our goal...

A cleft is a fissure or an opening. ${ }^{1} \mathrm{CLP}$ is the second commonest birth defect. ${ }^{2}$ It can occur as a single entity or as a combination. Cleft lip (CL) is caused due to the failure of fusion of the maxillary process with the medial nasal process during the 4th-5th week of intrauterine life. ${ }^{1}$ Cleft palate (CP) results from a lack of fusion of the palatine shelves. ${ }^{3}$

The World Health Organization in April 2012 reported that birth defects such as CLP occur in about 1 per $500-700$ of all live births. ${ }^{2}$ In India, the incidence of the cleft is 1 in every $600-1000$ births. ${ }^{4}$

No single factor can be considered to be responsible for the occurrence of CLP and, hence, the term multifactorial inheritance is used commonly. This term implicates the fact that CLP is under the influence of genetic as well as environmental factors. ${ }^{5}$

Fujino et al. ${ }^{6}$ reported that an increased incidence of CP in Japan was due to the increased frequency of consanguineous marriage. A positive association was found between the first-degree consanguinity and nonsyndromic CLP. Newcombe ${ }^{7}$ reported that this is because of the increase in homozygosity. Saaxen et al. ${ }^{8}$ found a strong positive association between CLP and antineurotic agents such as benzodiazepines.

Various problems associated with CLP include difficulty in feeding, hearing, and speech impairment, with other associated problems like psychological problems and dental problems. ${ }^{9}$

Feeding problems make it difficult to obtain adequate nutrition. This is due to the insufficient suction to pull milk from the nipple, excessive air intake during feeding thereby requiring several
${ }^{1}$ Department of Pedodontics and Preventive Dentistry, SRM Kattankulathur Dental College, Chennai, Tamil Nadu, India

${ }^{2}$ Department of Pedodontics and Preventive Dentistry, Vinayaka Missions Sankarachariyar Dental College, Salem, Tamil Nadu, India

${ }^{3}$ Department of Pedodontics, Vinayaka Missions Sankarachariyar Dental College, Salem, Tamil Nadu, India

Corresponding Author: Chrishantha Joybell, Department of Pedodontics and Preventive Dentistry, SRM Kattankulathur Dental College, Chennai, Tamil Nadu, India, Phone: +91 9384884693, e-mail: chrishanthajoybell@gmail.com

How to cite this article: Joybell C, Krishnan R, et al. Evaluation of Postsurgical Dentofacial Deformities in Children Operated for Correction of Cleft Lip and Palate-A Cross-sectional Study. Int J Clin Pediatr Dent 2019;12(3):165-177.

Source of support: Nil

Conflict of interest: None

burpings, choking, nasal discharge, and excessive time required for nourishment. ${ }^{10}$

With an increase in the severity of the cleft, the severity of the dental problems also increases. The most commonly affected tooth is the maxillary lateral incisor which is in the line of the cleft caused by the disruption of the dental lamina. Other anomalies may include agenesis of teeth, supernumerary teeth, concurrent agenesis, and supernumerary teeth within or adjacent the cleft and disorders of morphogenesis (size and shape). ${ }^{11}$

Usually, an interdisciplinary team approach to provide integrated cleft care is mandatory. ${ }^{4}$ Obturator construction aids in feeding for those infants born with complete CLP. Pashayan and $\mathrm{McNab}$ recommended using a standard crosscut nipple that provides improved ejection of milk into the infant's mouth with minimal effort. ${ }^{9}$ 
Preventive dental care is extremely important in the cleft patients as optimum dental health is essential for the total rehabilitation of the patients. ${ }^{4}$ The present day society demands from the medical and health profession the total personality development of such an individual so that he/she is not a stigma as well as a burden on the society. ${ }^{9}$

Surgical management of CLP is to be carried out at an appropriate age. Closure of the $\mathrm{CL}$ is initiated early which significantly improves the infant's appearance and may thereby relieve parental apprehensions and enhances acceptance of the child. ${ }^{12}$ Surgical closure of the $\mathrm{CL}$ may be accomplished shortly after birth. A general "rule of ten" (10 weeks of age, 10 pounds of body weight, and $10 \mathrm{~g}$ of hemoglobin and WBC count not less than 10,000 per cu mm of blood) is commonly used in determining optimal timing for lip closure. ${ }^{13}$ The commonest technique of $C L$ repair is Millard's rotation advancement technique, as it is a very simple design to execute. ${ }^{9}$

Closure of the palate is accomplished between 12 and 24 months of age. The primary purpose of palate closure by 2 years of age is to facilitate the acquisition of normal speech, because this correlates with the age at which most children develop speech. It also improves the quality of hearing and deglutition by the alignment of the CP musculature. ${ }^{12}$

Postsurgically, repair of the lip and palate can cause secondary growth disturbances like nasal form, nasal asymmetry, and distortion of the upper lip. There can be scarring of the philtral area with a diminished or absent philtral groove..$^{14,15}$

This study was mainly planned to bring about the significant relationship between the timing of CLP repair and the severity of extraoral and intraoral deformities.

\section{Materials and Methods}

The study was carried out in 100 children who were surgically managed for CLP by the Smile Train Center at the Vinayaka Missions Hitech Hospital, Salem. The children were randomly selected and were between the age group of 4 and 15 years, in which 57 were males and 43 were females.

Informed written consent was obtained from the parents of each child who participated in the study. Before the commencement of the study, ethical committee clearance was obtained from the Institutional Ethical Committee Board (Ref: VMSDC/IEC/Approval no. 014).

\section{Inclusion Criteria}

- Children who were surgically managed for CLP

- Ages between 4 and 15 years

- Children without any associated syndromes

\section{Exclusion Criteria}

- Patients who had undergone any presurgical orthopedic appliance therapy

- Patients who are undergoing any orthodontic treatment

- Patients who underwent any cosmetic surgery/orthognathic surgery/revision surgeries.

A detailed medical, personal, and family history was obtained from each child and their parents on a printed proforma. The type of cleft was noted according to Kernahan's stripped Y classification. A thorough intraoral and extraoral examination was done under visible daylight. Intraoral and extraoral photographs were taken using a digital camera and deformities were evaluated and recorded in the proforma obtained earlier (Figs 1 to 4).

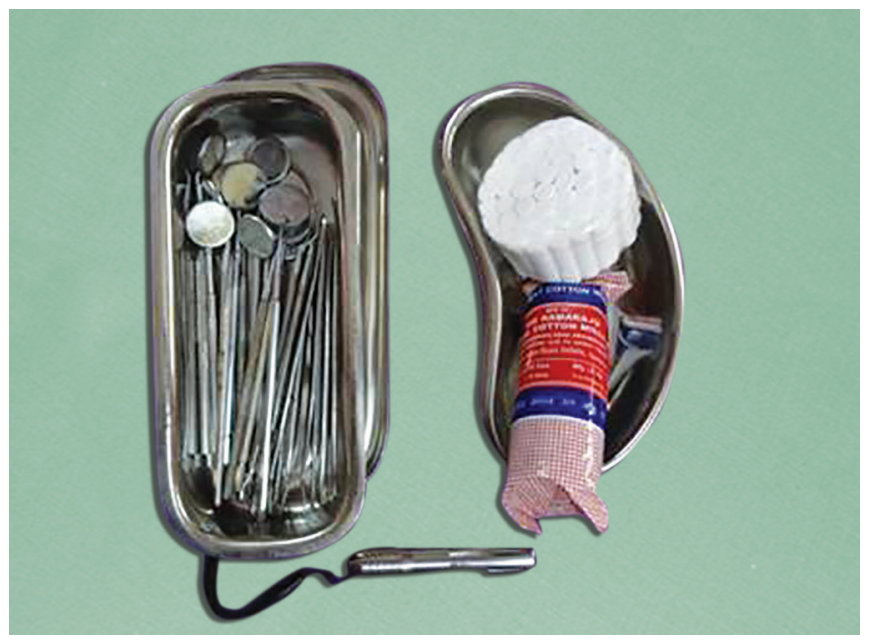

Fig. 1: Armamentarium for patient examination

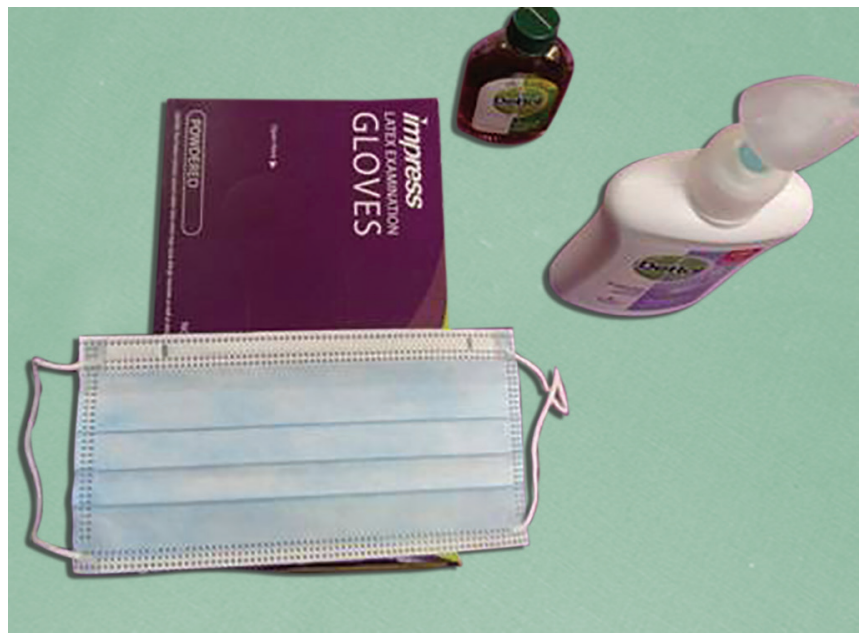

Fig. 2: Protective measures undertaken

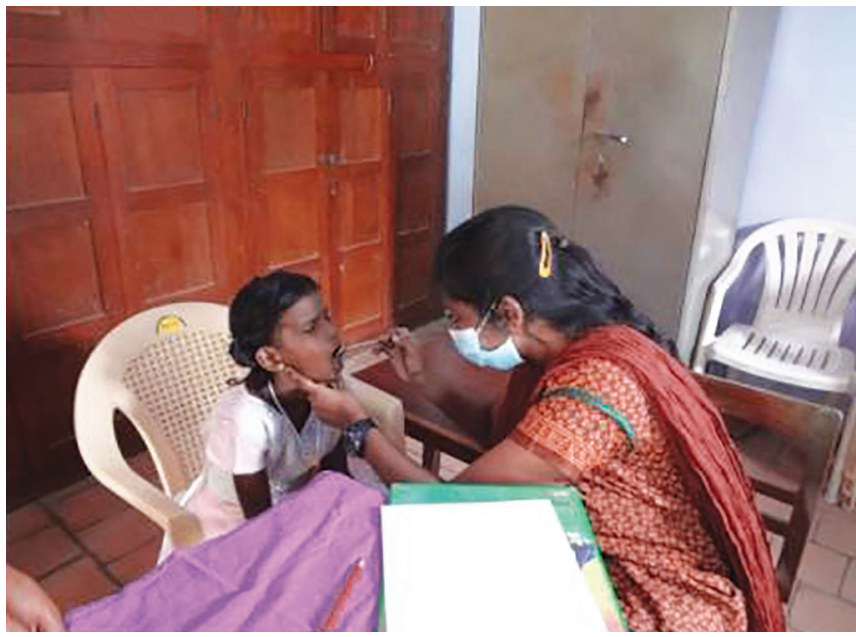

Fig. 3: Examination of patient

\section{Statistical Analysis}

The details, thus, obtained were subjected to statistical evaluation using SPSS 11.5 software and evaluated using the Chi-square test. 


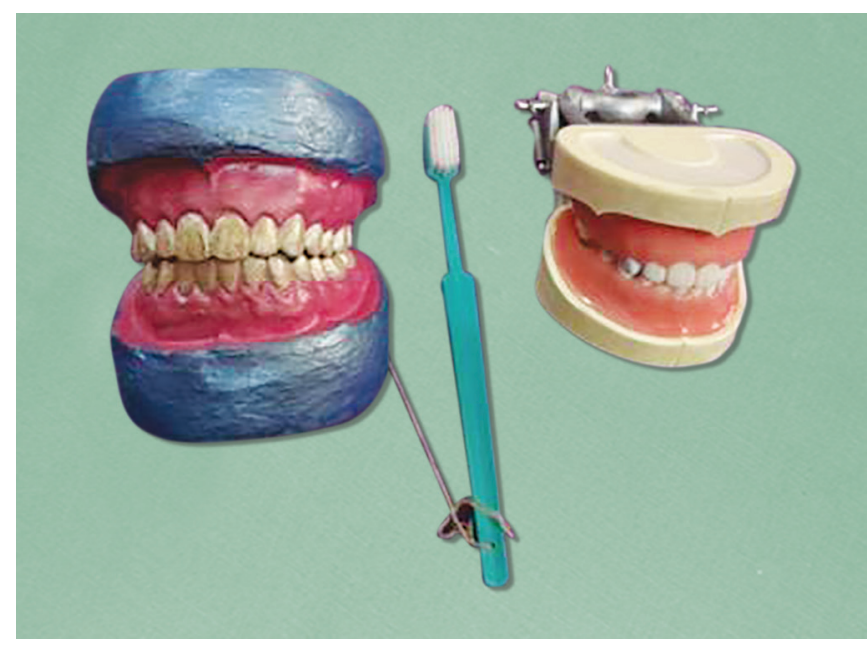

Fig. 4: Tooth brushing model to educate the CLP patients

\section{Results}

The overall distribution of children with CLP showed unilateral cleft lip and palate (UCLP) with $51 \%$ followed by bilateral cleft lip and palate (BCLP) with $29 \%$ and CL with $13 \%$ (Table 1). When the timing of lip repair was assessed for extraoral dentofacial deformities, nasal septum deviation, notching of the upper lip, short upper lip, cupid's bow distortion, deficient vermillion border, flattened ala of nose, the presence of extraoral scar was noticed between 0 and 1 year of age following repair which was statistically significant with a $p$ value of 0.001 (Table 2).

When the timing of lip repair was assessed for intraoral dentofacial deformities, the occurrence of cleft in the alveolus, premaxillary protrusion, congenitally missing tooth, hypodontia, aberrations in crown shape, microdontia, rotation of tooth and hypoplasia were noticed when the lip repair was done between 0 and 1 year of age and it was statistically significant with a $p$ value of 0.001 (Tables 3 and 4). The timing of palatal repair did not have any significant influence on the severity of the extraoral dentofacial deformities (Table 5). The timing of palatal repair had a significant influence on the severity of upper arch constriction, premaxillary protrusion, supernumerary teeth and hypodontia which was statistically significant with a $p$ value of 0.001 (Table 6).

\section{Discussion}

CLP is a common birth defect that affects all major racial and ethnic groups of the population. They present with a wide range of skeletal

Table 1: Distribution of the cleft deformity in cleft lip palate cases

\begin{tabular}{|c|c|c|c|c|c|c|}
\hline \multirow[b]{3}{*}{ Distribution of cleft deformity } & \multicolumn{4}{|l|}{ Sex } & \multirow{2}{*}{\multicolumn{2}{|c|}{ Total }} \\
\hline & \multicolumn{2}{|c|}{ Male } & \multicolumn{2}{|c|}{ Female } & & \\
\hline & $N$ & $\%$ & $N$ & $\%$ & $N$ & $\%$ \\
\hline Bilateral CLP & 15 & 15 & 14 & 14 & 29 & 29 \\
\hline Unilateral CLP & 33 & 33 & 18 & 18 & 51 & 51 \\
\hline Cleft of lip only & 6 & 6 & 7 & 7 & 13 & 13 \\
\hline Cleft of palate only & 1 & 1 & 1 & 1 & 2 & 2 \\
\hline Median cleft & 2 & 2 & 3 & 3 & 5 & 5 \\
\hline Total & 57 & 57 & 43 & 43 & 100 & 100 \\
\hline
\end{tabular}

Table 2: Association b/w timing of lip repair and extraoral dentofacial deformities

\begin{tabular}{|c|c|c|c|c|c|c|c|c|c|c|c|c|c|c|c|c|}
\hline & & \multicolumn{12}{|c|}{ Timing of lip repair } & \multirow[b]{3}{*}{ Total } & \multirow[b]{3}{*}{ Chi-square } & \multirow[b]{3}{*}{$p$-value } \\
\hline & & \multicolumn{2}{|c|}{0} & \multicolumn{2}{|c|}{$0-1$ year } & \multicolumn{2}{|c|}{$1-2$ years } & \multicolumn{2}{|c|}{$2-3$ years } & \multicolumn{2}{|c|}{ 4-6 years } & \multicolumn{2}{|c|}{ 7-9years } & & & \\
\hline & & $N$ & $\%$ & $N$ & $\%$ & $N$ & $\%$ & $N$ & $\%$ & $N$ & $\%$ & $N$ & $\%$ & & & \\
\hline \multirow[t]{2}{*}{ Nasal septum deviation } & Yes & 1 & 1 & 61 & 61 & 18 & 18 & 4 & 4 & 7 & 7 & 3 & 3 & 94 & 21.93 & $0.001^{* *}$ \\
\hline & No & 2 & 2 & 2 & 2 & 2 & 2 & & & & & & & 6 & & \\
\hline \multirow[t]{2}{*}{ Notching of lip } & Yes & & & 63 & 63 & 19 & 19 & 4 & 4 & 7 & 7 & 3 & 3 & 96 & 75.26 & $<0.001^{* *}$ \\
\hline & No & 3 & 3 & & & 1 & 1 & & & & & & & 4 & & \\
\hline \multirow[t]{2}{*}{ Short upper lip } & Yes & & & 63 & 63 & 18 & 18 & 4 & 4 & 7 & 7 & 3 & 3 & 95 & 62.11 & $<0.001^{* *}$ \\
\hline & No & 3 & 3 & & & 2 & 2 & & & & & & & 5 & & \\
\hline \multirow[t]{2}{*}{ Cupid's bow distortion } & Yes & & & 63 & 63 & 19 & 19 & 4 & 4 & 7 & 7 & 3 & 3 & 96 & 75.26 & $<0.001^{* *}$ \\
\hline & No & 3 & 3 & & & 1 & 1 & & & & & & & 4 & & \\
\hline \multirow[t]{2}{*}{ Deficient vermillion border } & Yes & & & 63 & 63 & 18 & 18 & 4 & 4 & 7 & 7 & 3 & 3 & 95 & 62.11 & $<0.001^{* *}$ \\
\hline & No & 3 & 3 & & & 2 & 2 & & & & & & & 5 & & \\
\hline \multirow[t]{2}{*}{ Flattened ala of nose } & Yes & & & 63 & 63 & 18 & 18 & 4 & 4 & 7 & 7 & 3 & 3 & 95 & 62.11 & $<0.001^{* *}$ \\
\hline & No & 3 & 3 & & & 2 & 2 & & & & & & & 5 & & \\
\hline \multirow[t]{2}{*}{ Presence of scar } & Yes & & & 63 & 63 & 20 & 20 & 4 & 4 & 7 & 7 & 3 & 3 & 97 & 100.00 & $<0.001^{* *}$ \\
\hline & No & 3 & 3 & & & & & & & & & & & 3 & & \\
\hline Total & 3 & 3 & 63 & 63 & 20 & 20 & 4 & 4 & 7 & 7 & 3 & 3 & 100 & & & \\
\hline
\end{tabular}

*Significant at $5 \%$

**Significant at $1 \%$ 
Table 3: Association b/w timing of lip repair and intraoral dentofacial deformities

\begin{tabular}{|c|c|c|c|c|c|c|c|c|c|c|c|c|c|c|c|c|}
\hline & & \multicolumn{12}{|c|}{ Timing of lip repair } & \multirow[b]{3}{*}{ Total } & \multirow[b]{3}{*}{ Chi-square } & \multirow[b]{3}{*}{$p$-value } \\
\hline & & \multicolumn{2}{|l|}{0} & \multicolumn{2}{|c|}{$0-1$ year } & \multicolumn{2}{|c|}{$1-2$ years } & \multicolumn{2}{|c|}{$2-3$ years } & \multicolumn{2}{|c|}{ 4-6 years } & \multicolumn{2}{|c|}{ 7-9 years } & & & \\
\hline & & $N$ & $\%$ & $N$ & $\%$ & $N$ & $\%$ & $N$ & $\%$ & $N$ & $\%$ & $N$ & $\%$ & & & \\
\hline \multirow[t]{2}{*}{ Anterior crossbite } & Yes & 1 & 1 & 44 & 44 & 15 & 15 & 3 & 3 & 7 & 7 & 2 & 2 & 72 & 5.24 & 0.387 \\
\hline & No & 2 & 2 & 19 & 19 & 5 & 5 & 1 & 1 & & & 1 & 1 & 28 & & \\
\hline \multirow[t]{2}{*}{ Posterior unilateral crossbite } & Yes & & & 12 & 12 & 2 & 2 & & & 2 & 2 & & & 16 & 3.70 & 0.594 \\
\hline & No & 3 & 3 & 51 & 51 & 18 & 18 & 4 & 4 & 5 & 5 & 3 & 3 & 84 & & \\
\hline \multirow[t]{2}{*}{ Posterior bilateral crossbite } & Yes & & & 22 & 22 & 9 & 9 & 3 & 3 & 4 & 4 & 1 & 1 & 39 & 5.85 & 0.321 \\
\hline & No & 3 & 3 & 41 & 41 & 11 & 11 & 1 & 1 & 3 & 3 & 2 & 2 & 61 & & \\
\hline \multirow[t]{2}{*}{ Upper arch constriction } & Yes & 3 & 3 & 60 & 60 & 19 & 19 & 4 & 4 & 7 & 7 & 2 & 2 & 95 & 5.81 & 0.325 \\
\hline & No & & & 3 & 3 & 1 & 1 & & & & & 1 & 1 & 5 & & \\
\hline \multirow[t]{2}{*}{ Residual fistula in palate } & Yes & 1 & 1 & 21 & 21 & 8 & 8 & & & 2 & 2 & & & 32 & 3.97 & 0.553 \\
\hline & No & 2 & 2 & 42 & 42 & 12 & 12 & 4 & 4 & 5 & 5 & 3 & 3 & 68 & & \\
\hline \multirow[t]{2}{*}{ Cleft in alveolus } & Yes & & & 59 & 59 & 16 & 16 & 2 & 2 & 5 & 5 & 2 & 2 & 84 & 25.29 & $<0.001^{* *}$ \\
\hline & No & 3 & 3 & 4 & 4 & 4 & 4 & 2 & 2 & 2 & 2 & 1 & 1 & 16 & & \\
\hline Total & & 3 & 3 & 63 & 63 & 20 & 20 & 4 & 4 & 7 & 7 & 3 & 3 & 100 & & \\
\hline
\end{tabular}

*Significant at $5 \%$

**Significant at $1 \%$

and dental abnormalities even after they undergo any primary surgical correction. This study is focused mainly to evaluate the various postsurgical dentofacial deformities in surgically managed CLP patients.

Surgical repair of the CLP leads to various secondary growth disturbances including anomalies in nasal form, nasal asymmetry, and distortion of the upper lip. Various skeletal deformities also exist in all unilateral CLP due to the abnormal growth of the skeleton during the pre- and the postnatal period.

In the present study, the etiology associated with the occurrence of CLP was predominantly seen in children whose parents had a history of consanguinous marriage constituting to $44 \%$ among the various other etiological factors of CLP. This was similarly reported by Jabber et al., ${ }^{16}$ Alamoudi et al., ${ }^{17}$ and Fujino et al. ${ }^{18}$ who stated that most of the CLP children were born for parents who had a history of consanguinity.

In the present study, this familial tendency for CLP was noted in $13 \%$. This was similar to the study reported by Drillien et al. ${ }^{19}$ where one in three children with CLP had some relatives with similar congenital defects and thereby suggested that genetic factor plays as the most important causative factor in CLP.

The number of children with UCLP was found to be more common with $51 \%$ similar to a study reported by Manyama et al. ${ }^{20}$ with a male predilection. The present study showed that deformities seen were $48 \%$ in males and $42 \%$ in females with a ratio of $8: 7$ which is in accordance with a study reported by Marilyn ${ }^{21}$ who reported that CLP occurs twice as often in boys as in girls.

Kernahan ${ }^{22}$ suggested that Kernahan's stripped Y classification not only acts as a symbolic representation of the CLP deformity but also describes the exact condition of the patient embryologically, clinically, and pathologically. So this classification was preferred in the study as it was found to be very simple, reproducible, and it describes the progress of the patient before, during, and after treatment.

\section{Extraoral Deformities (Figs 5 to 15)}

In the present study, $40 \%$ of the children presented with a concave profile, $43 \%$ with convex profile, $17 \%$ with a straight profile, $26 \%$ of the males, and $14 \%$ of females had a concave profile. This was similarly reported by Paradowska-Stolarz ${ }^{23}$ who found in his study that CLP-affected boys had a significantly longer mandibular ramal length when compared to girls.

Bichara et al. ${ }^{24}$ reported that impaired maxillary sagittal growth was observed in patients with UCLP as a consequence of lip surgical repair which was similarly observed in the present study also wherein $59 \%$ of the children had disturbances in the maxillary growth after the primary repairs.

Most of the children in the present study was noted with deficient maxilla and this was similar to the study by Kremenak et al. ${ }^{25}$ and Farronato et al. ${ }^{26}$ who reported that lip repair could have a negative influence on the maxillary growth and they suggested that the best timing to carry out a lip repair would be between the third and the sixth month of age.

A study reported by Bishara et al. ${ }^{27}$ in patients repaired with unilateral CLP, the nasal septum and columella were deviated towards the non-cleft side from the facial midline and this was similarly found in the present study also.

Pensler ${ }^{28}$ reported that when direct lip repair is done, the tension caused when the segments are approximated leading to variouspostsurgical deformities of lip like notching of the upper lip, cupid's bow distortion, short upper lip, deficient vermilion border, flattened ala of nose and presence of extraoral scar. In the present study, $96 \%$ of the children showed notching of the upper lip with cupid's bow distortion; $95 \%$ had a short upper lip, deficient vermilion border, and flattened ala of nose; $97 \%$ showed the presence of an extraoral scar.

Similarly Mulliken ${ }^{29}$ reported that in children operated for CLP, the philtrum is bowed, wide, undimpled, asymmetric, and lacks a white ridge and this is because the prolabial vermillion mucosa is preserved and the lateral labial elements hang like swags. 
Table 4: Association b/w timing of lip repair and intraoral dentofacial deformities

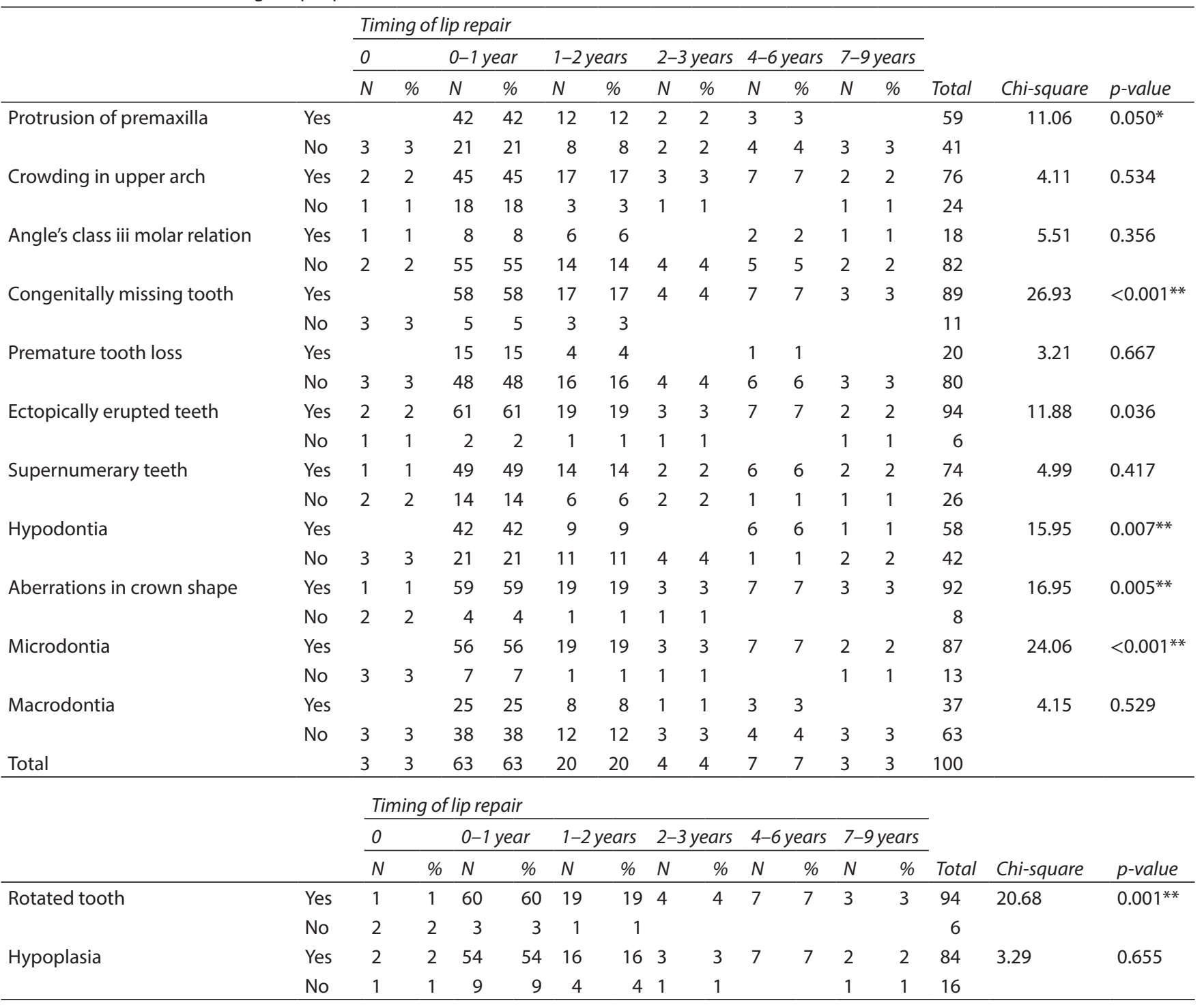

*Significant at $5 \%$

**Significant at $1 \%$

\section{Intraoral Deformities (Figs 16 to 33)}

Lithovius et al. ${ }^{30}$ and Hardwicke et al. ${ }^{31}$ evaluated the incidence of fistula inthe palate of surgically managed CLP patients and reported that patients with CLP were more likely to develop postoperative palatal fistulas than patients with CP. About $32 \%$ of the children in the present study who were surgically managed for CLP had a residual fistula in the palate.

Galante et al. ${ }^{32}$ stated that dental anomalies are extremely common in children with CLP. As the severity of the cleft increases, the number and the severity of the patient's dental problem also increase. One of the characteristic findings was that most of the dental anomalies were present along the line of the cleft.

\section{Dental Anomalies}

Shi et al. ${ }^{33}$ reported that deformed dental arch is a common postsurgical deformity in CLP patients. The present study also shows that a large number of children about $76 \%$ had crowding of teeth in the upper arch with 95\% having upper arch constriction.

Paradowska Stolarz et al. ${ }^{34}$ reported that the commonest malocclusions seen in patients with clefts were crossbites and class III malocclusions. It was also supported by another study done by Hellquist et al. ${ }^{35}$ where there was a high prevalence of anterior crossbite. In this present study when the crossbite was evaluated, $72 \%$ of the children had an anterior crossbite, $16 \%$ posterior unilateral crossbite, and 39\% showed bilateral posterior crossbite.

Tereza $^{36}$ reported that enamel structural alterations are frequent in permanent central incisors adjacent to the alveolar cleft and $84 \%$ of the children presented with hypoplastic teeth in the present study.

Obłoj et al. ${ }^{37}$ reported that hypodontia was the most common dental defect in the line of the cleft and it was found similarly in the 
present study with $58 \%$ of hypodontia and it was seen commonly close to the line of cleft. Premolar hypodontia was also seen in the children in the present study which was found to be similar to the study reported by Olin et al. ${ }^{38}$

Peg laterals, another dental anomaly, were reported by Maciel et al. ${ }^{39}$ which present a high prevalence of shape alterations. In the permanent dentition, the lateral incisor may be missing in $20-26 \%$ of cases of UCL and in $50 \%$ of complete UCLP which was also found to be in accordance with the present study where $89 \%$ of the children had congenitally missing teeth.

Ectopic eruption of teeth was seen in $94 \%$ and this was similar to a study reported by Olievera Lima et al. ${ }^{40}$ who reported a high prevalence of ectopic eruption of the permanent maxillary first molar in surgically managed CLP patients, whereas Silva ${ }^{41}$ reported that ectopic eruption of the maxillary first molar was observed in $20 \%$ of individuals with complete CLP.

About $74 \%$ of the cases in the study had the presence of supernumerary teeth. This was in accordance with a study reported by Fishman ${ }^{42}$ who suggested that patients with CLP presented a high prevalence of hypodontia and supernumerary teeth and this could be due to a genetic component.

Surgical management of CLP should be carried out at an appropriate age. In the present study, $63 \%$ of the children who underwent direct lip repair before 1 year of age had nasal septum deviation, notching of lips, short upper lip, cupid's bow distortion, deficient vermillion border, and flattened ala of the nose which were all statistically significant. All these findings were reported similarly by the studies conducted by Filho and Saunders et al. ${ }^{43}$

Among the intraoral deformities, the timing of lip repair has a significant influence on the occurrence of the cleft in the alveolus, premaxillary protrusion, congenitally missing a tooth, hypodontia, aberrations in a crown shape, microdontia, rotation of tooth, and hypoplasia when lip repair was done before 1 year of age. This was in accordance with a study report by Krauss et al. ${ }^{44}$ who suggested that trauma from early surgical repair of CLP and related scar tissue formation contributes to the presence of hypoplastic and missing incisors on the cleft side.

However, the present study here observed that the timing of repair of cleft palate does not significantly influence the occurrence of dentofacial anomalies. Trindade et al. ${ }^{45}$ also suggested that it is the lip repair that adversely affects dentofacial morphology rather than the palatal surgery.

The findings from the present study suggest poor dental arch relations in the majority of the cases who were surgically managed for CLP. So this study shows that there is a need to supplement a definitive treatment protocol to manage the postsurgical deformities. Future studies can be directed towards analyzing the type of repair undertaken during the surgical procedure.

\section{Conclusion}

CLP can present with considerable variation in severity and form. Generally, the wider and more extensive clefts are associated with the significant dentofacial deformity. Direct surgical repair of the lip and palate leads to various secondary growth disturbances including anomalies in nasal form, nasal asymmetry, and distortion of the upper lip. 
Table 6: Association b/w timing of palatal repair and intraoral dentofacial deformities

\begin{tabular}{|c|c|c|c|c|c|c|c|c|c|c|c|c|c|c|c|c|c|c|c|c|c|}
\hline & & \multicolumn{18}{|c|}{ Timing of palatal repair } & \multirow{3}{*}{$\begin{array}{l}\text { Chi- } \\
\text { square }\end{array}$} & \multirow[b]{3}{*}{$p$-value } \\
\hline & & \multicolumn{3}{|l|}{0} & \multicolumn{2}{|c|}{ 0-1 year } & \multicolumn{2}{|c|}{$1-2$ years } & \multicolumn{2}{|c|}{$2-3$ years } & \multicolumn{2}{|c|}{ 4-6 years } & \multicolumn{2}{|c|}{ 7-9 years } & \multicolumn{2}{|c|}{$9-12$ years } & \multicolumn{3}{|c|}{ 12- 14 years } & & \\
\hline & & $N$ & $\%$ & & $N$ & $\%$ & $N$ & $\%$ & $N$ & $\%$ & $N$ & $\%$ & $N$ & $\%$ & $N$ & $\%$ & $N$ & $\%$ & & & \\
\hline \multirow[t]{2}{*}{ Anterior crossbite } & Yes & 7 & 12. & & 0.086 & 92 & 28 & 28 & 10 & 10 & 5 & 5 & 6 & 6 & 6 & 6 & 1 & 1 & & 12.48 & 0.086 \\
\hline & No & 7 & & & & 1 & 8 & 8 & 9 & 9 & 2 & 2 & & & 1 & 1 & & & & 28 & \\
\hline Posterior unilateral & Yes & 1 & 12. & & 0.097 & 5 & 6 & 6 & 3 & 3 & & & & & 1 & 1 & & & & 12.11 & 0.097 \\
\hline crossbite & No & 13 & & & & 5 & 30 & 30 & 16 & 16 & 7 & 7 & 6 & 6 & 6 & 6 & 1 & 1 & & 84 & \\
\hline Posterior bilateral & Yes & 1 & 13. & & 0.052 & 4 & 14 & 14 & 6 & 6 & 5 & 5 & 4 & 4 & 4 & 4 & 1 & 1 & & 13.97 & 0.052 \\
\hline crossbite & No & 13 & & & & 6 & 22 & 22 & 13 & 13 & 2 & 2 & 2 & 2 & 3 & 3 & & & & 61 & \\
\hline Upper arch & Yes & 10 & 19. & & 0.006 & 10 & 36 & 36 & 18 & 18 & 7 & 7 & 6 & 6 & 7 & 7 & 1 & 1 & & 19.91 & $0.006^{* *}$ \\
\hline constriction & No & 4 & & & & & & & 1 & 1 & & & & & & & & & & 5 & \\
\hline Residual fistula in & Yes & 1 & 12. & & 0.087 & 2 & 16 & 16 & 7 & 7 & 1 & 1 & 3 & 3 & 1 & 1 & 1 & 1 & & 12.44 & 0.087 \\
\hline palate & No & 13 & & & & 8 & 20 & 20 & 12 & 12 & 6 & 6 & 3 & 3 & 6 & 6 & & & & 68 & \\
\hline Cleft in alveolus & Yes & 10 & 11. & & 0.122 & 10 & 33 & 33 & 15 & 15 & 5 & 5 & 6 & 6 & 4 & 4 & 1 & 1 & & 11.40 & 0.122 \\
\hline & No & 4 & 4 & & & & 3 & 3 & 4 & 4 & 2 & 2 & & & 3 & 3 & & & & 16 & \\
\hline Total & & 14 & 14 & & 10 & 10 & 36 & 36 & 19 & 19 & 7 & 7 & 6 & 6 & 7 & 7 & 1 & 1 & & 100 & \\
\hline & & & ming & of $p$ & salatal & repair & & & & & & & & & & & & & & & \\
\hline & & 0 & & & -1 yea & $\operatorname{ar} 1-2$ & -2 years & $s \quad 2-3$ & 3 yea & & 4-6 yea & & 7-9year & & $9-12$ yea & & $12-1$ & tyears & & Chi- & \\
\hline & & $N$ & $\%$ & $N$ & $\%$ & $N$ & $\%$ & $N$ & & $\%$ & $\%$ & $N$ & $\%$ & & $\%$ & $N$ & N & $\%$ & Toto & square & $p$-value \\
\hline Protrusion of pre- & Yes & 3 & 3 & 3 & 5 & 27 & 27 & 10 & & 10 & 5 & 6 & 6 & & 2 & 1 & 1 & 1 & 59 & 20.62 & $0.004^{* * *}$ \\
\hline maxilla & No & 11 & 1 & 1 & 5 & 9 & 9 & 9 & & 9 & 2 & & & 5 & 5 & & & & 41 & +1 & \\
\hline Crowding in upper & Yes & 10 & 1 & 0 & 8 & $8 \quad 24$ & 24 & 14 & & 14 & 7 & 6 & 6 & & 6 & 1 & 1 & 1 & 76 & 6.81 & 0.449 \\
\hline & No & $<$ & 4 & 4 & 2 & 212 & 12 & 5 & & 5 & & & & & 1 & & & & 24 & 24 & \\
\hline Angle's class III & Yes & 5 & 5 & 5 & 1 & 6 & 6 & 3 & & 3 & & 2 & 2 & & 1 & & & & 18 & 6.29 & 0.506 \\
\hline molar relation & No & s & 9 & 9 & 9 & 930 & 30 & 16 & & 16 & 7 & 4 & 4 & & 6 & 1 & 1 & 1 & 82 & 32 & \\
\hline Congenitally miss- & Yes & 11 & 1 & 1 & 9 & 32 & 32 & 16 & & 16 & 7 & 6 & 6 & & 7 & 1 & 1 & 1 & 89 & 4.61 & 0.708 \\
\hline ing tooth & No & 3 & 3 & 3 & 1 & 4 & 4 & 3 & & 3 & & & & & & & & & 11 & 1 & \\
\hline Premature tooth & Yes & 2 & 2 & 2 & 2 & 26 & 6 & 5 & & 5 & 2 & 3 & 3 & & & & & & 20 & 6.71 & 0.460 \\
\hline loss & No & 12 & 1 & 2 & 8 & $8 \quad 30$ & 30 & 14 & & 14 & 5 & 3 & 3 & 7 & 7 & 1 & 1 & 1 & 80 & 30 & \\
\hline Ectopically erupted & Yes & 12 & 1 & 21 & 10 & 35 & 35 & 17 & & 17 & 6 & 6 & 6 & & 7 & 1 & 1 & 1 & 94 & 5.44 & 0.606 \\
\hline teeth & No & 2 & 2 & 2 & & 1 & 1 & 2 & & 2 & 1 & & & & & & & & & 6 & \\
\hline Supernumerary & Yes & 5 & 5 & 5 & 8 & $8 \quad 31$ & 31 & 13 & & 13 & 4 & 6 & 6 & & 6 & 1 & 1 & 1 & 74 & 17.90 & $0.012^{*}$ \\
\hline teeth & No & s & 9 & 9 & 2 & 5 & 5 & 6 & & 6 & 3 & & & 1 & 1 & & & & 26 & 26 & \\
\hline Hypodontia & Yes & 3 & 3 & 3 & 8 & $8 \quad 23$ & 23 & 10 & & 10 & 2 & 5 & 5 & & 6 & 1 & 1 & 1 & 58 & 17.41 & $0.015^{*}$ \\
\hline & No & 11 & 1 & 1 & 2 & 213 & 13 & 9 & & 9 & 5 & 1 & 1 & 1 & 1 & & & & 42 & 12 & \\
\hline Aberrations in & Yes & 12 & 1 & 2 & 9 & 35 & 35 & 16 & & 16 & 6 & 6 & 6 & 7 & 7 & 1 & 1 & 1 & 92 & 5.30 & 0.623 \\
\hline crown shape & No & 2 & 2 & 2 & 1 & 1 & 1 & 3 & & 3 & 1 & & & & & & & & & 8 & \\
\hline Microdontia & Yes & 11 & 1 & 1 & 8 & $8 \quad 33$ & 33 & 15 & & 15 & 6 & 6 & 6 & & 7 & 1 & 1 & 1 & 87 & 5.20 & 0.636 \\
\hline & No & 3 & 3 & 3 & 2 & 3 & 3 & 4 & & 4 & 1 & & & & & & & & 13 & 3 & \\
\hline Macrodontia & Yes & 2 & 4 & 4 & 6 & $6 \quad 15$ & 15 & 6 & & 6 & 2 & 2 & 2 & & 1 & 1 & 1 & 1 & 37 & 6.77 & 0.453 \\
\hline & No & 10 & 1 & 0 & 4 & $4 \quad 21$ & 21 & 13 & & 13 & 5 & 4 & 4 & 6 & 6 & & & & 63 & 33 & \\
\hline Total & & 14 & 1 & $4 \quad 1$ & $10 \quad 10$ & $0 \quad 36$ & 36 & 19 & & 19 & 7 & 6 & 6 & 7 & 7 & 1 & 1 & 1 & 100 & 0 & \\
\hline & & Timi & ing o & fpalc & latal re & epair & & & & & & & & & & & & & & & \\
\hline & & 0 & & $0-1$ & year & $1-2 y \epsilon$ & years & $2-3 y$ & jears & & 6 years & $7-9$ & years & & 12 years & $12-1$ & $-14 y$ & ears & & & \\
\hline & & $N$ & $\%$ & $N$ & $\%$ & $N$ & $\%$ & $N$ & $\%$ & $N$ & $\%$ & $N$ & $\%$ & $N$ & $\%$ & $N$ & & $\%$ & Total & Chi-square & $p$-value \\
\hline Rotated tooth & Yes & 12 & 12 & 10 & 10 & 35 & 35 & 16 & 16 & 7 & 7 & 6 & 6 & 7 & 7 & 1 & & 1 & 94 & 7.57 & 0.372 \\
\hline & No & 2 & 2 & & & 1 & 1 & 3 & 3 & & & & & & & & & & 6 & & \\
\hline Hypoplasia & Yes & 9 & 9 & 9 & 9 & 33 & 33 & 14 & 14 & 5 & 5 & 6 & 6 & 7 & 7 & 1 & & 1 & 84 & 10.88 & 0.144 \\
\hline & No & 5 & 5 & 1 & 1 & 3 & 3 & 5 & 5 & 2 & 2 & & & & & & & & 16 & & \\
\hline & No & 9 & 9 & 2 & 2 & 11 & 11 & 9 & 9 & 3 & 3 & 2 & 2 & 1 & 1 & & & & 37 & & \\
\hline Total & & 14 & 14 & 10 & 10 & 36 & 36 & 19 & 19 & 7 & 7 & 6 & 6 & 7 & 7 & 1 & & 1 & 100 & & \\
\hline
\end{tabular}




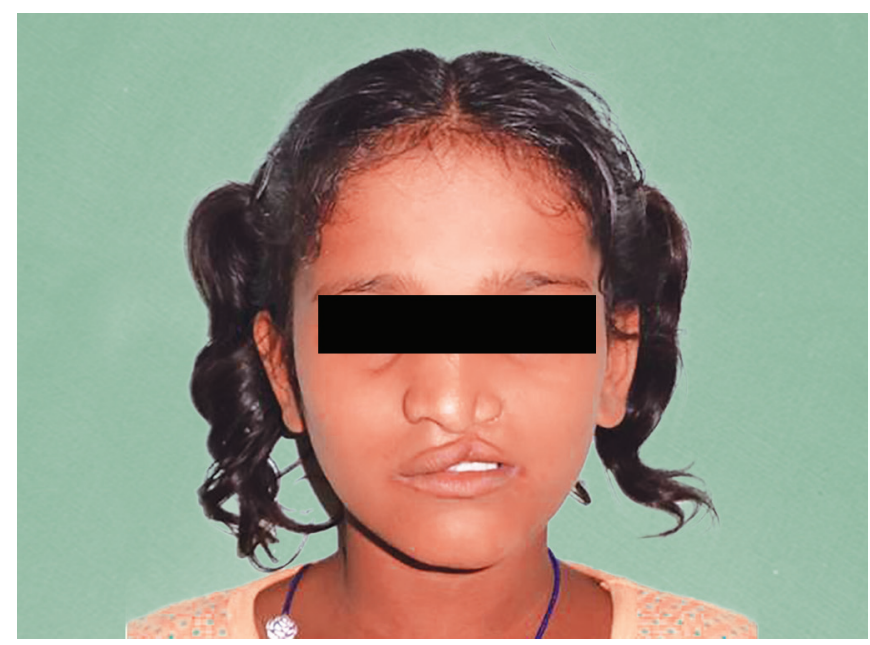

Fig. 5: Nasal septum deviation and notching of lip

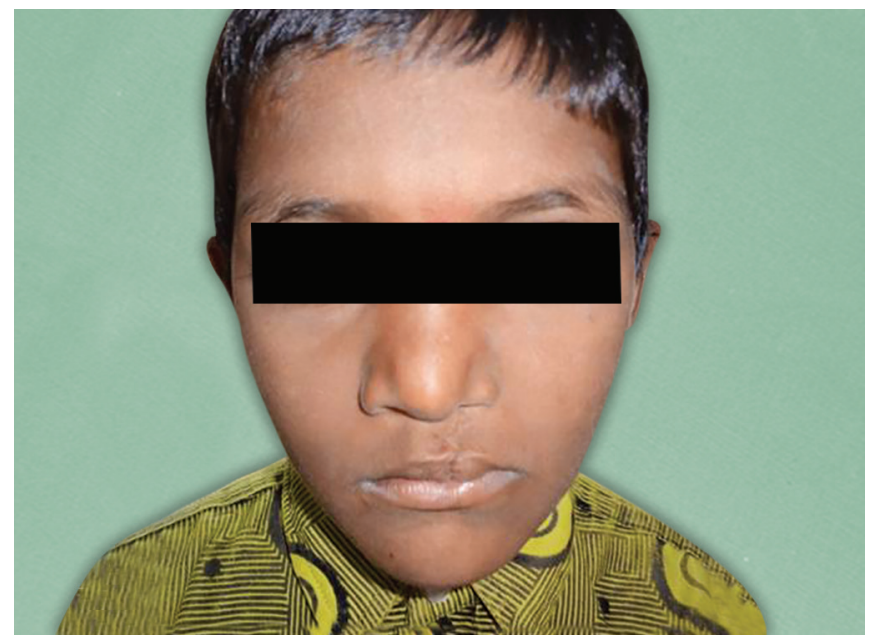

Fig. 7: Cupid's bow distortion

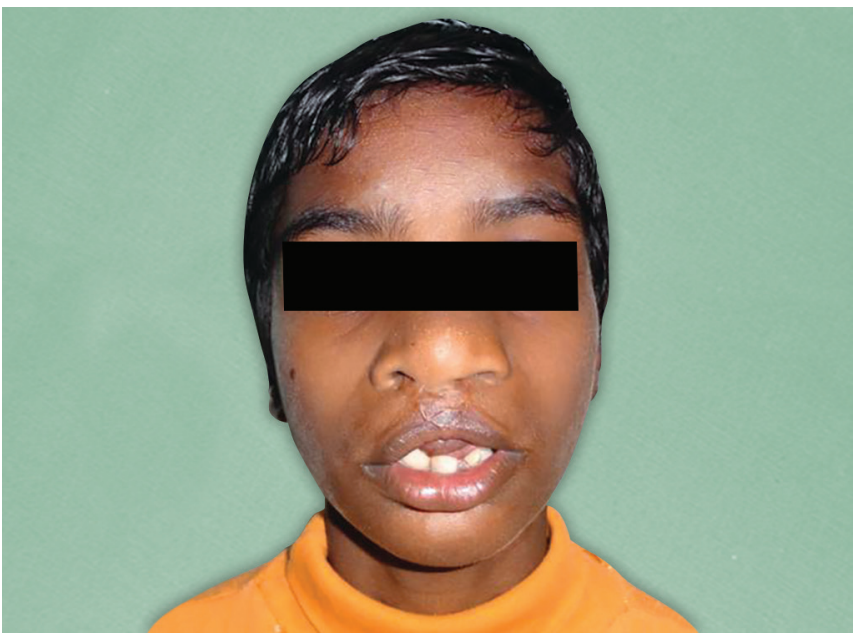

Fig. 9: Flattened ala of nose

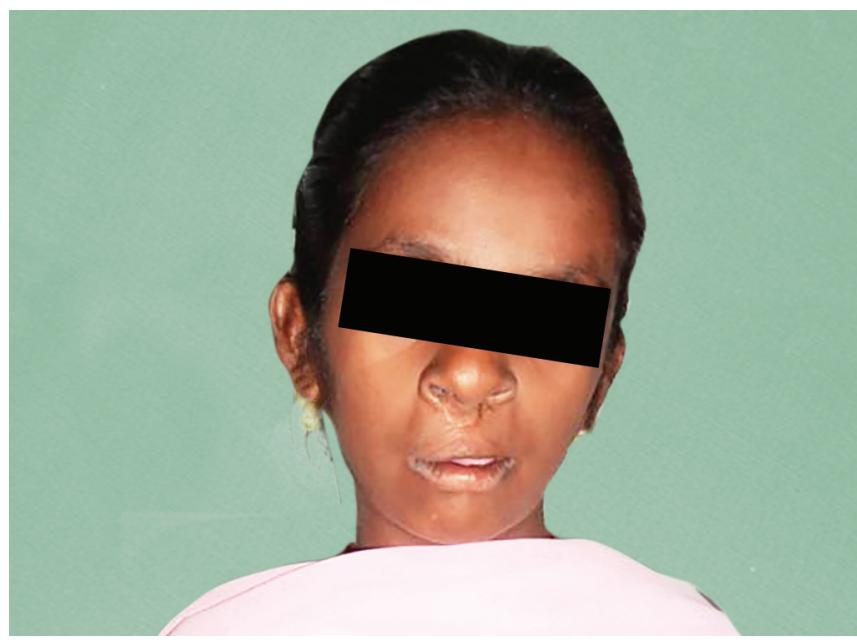

Fig. 6: Short upper lip

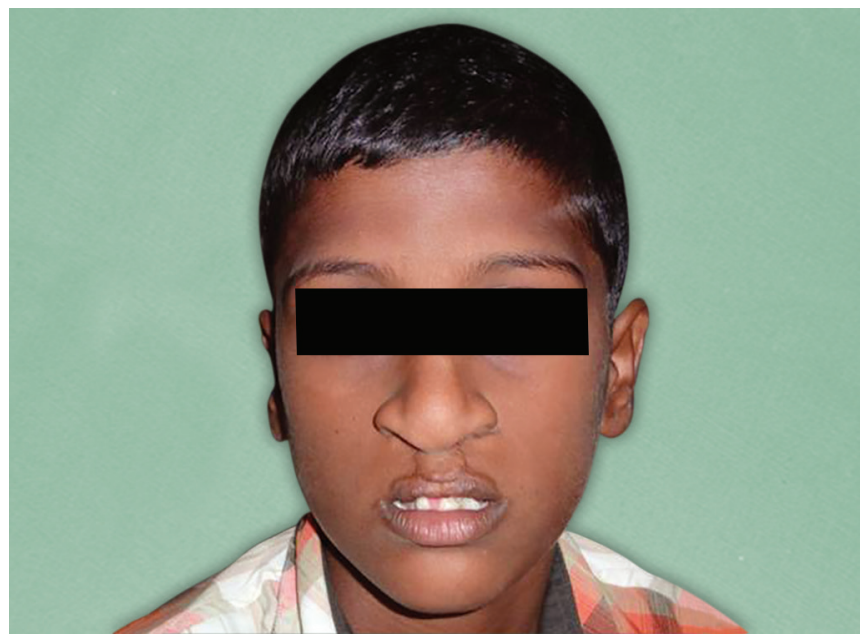

Fig. 8: Deficient vermilion border

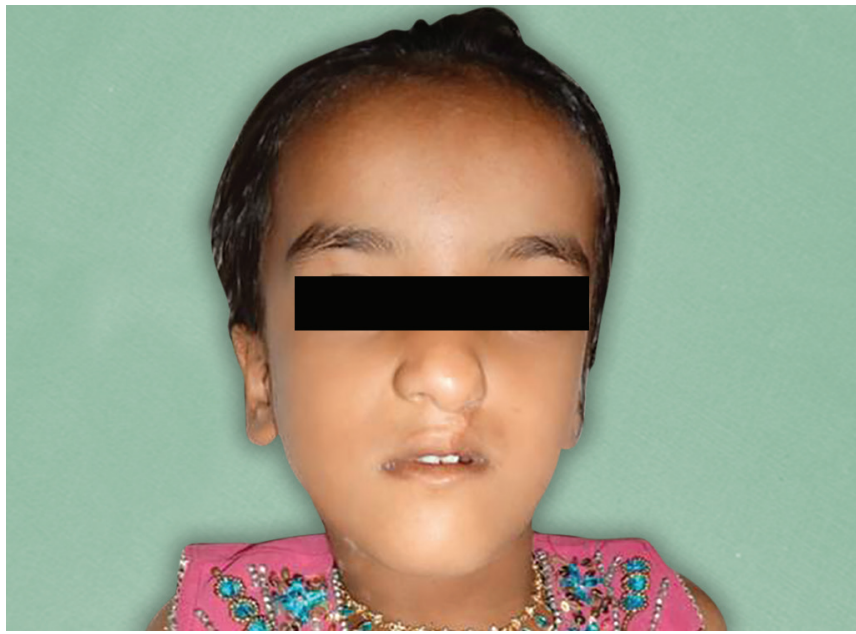

Fig. 10: Flattened dome of nose 


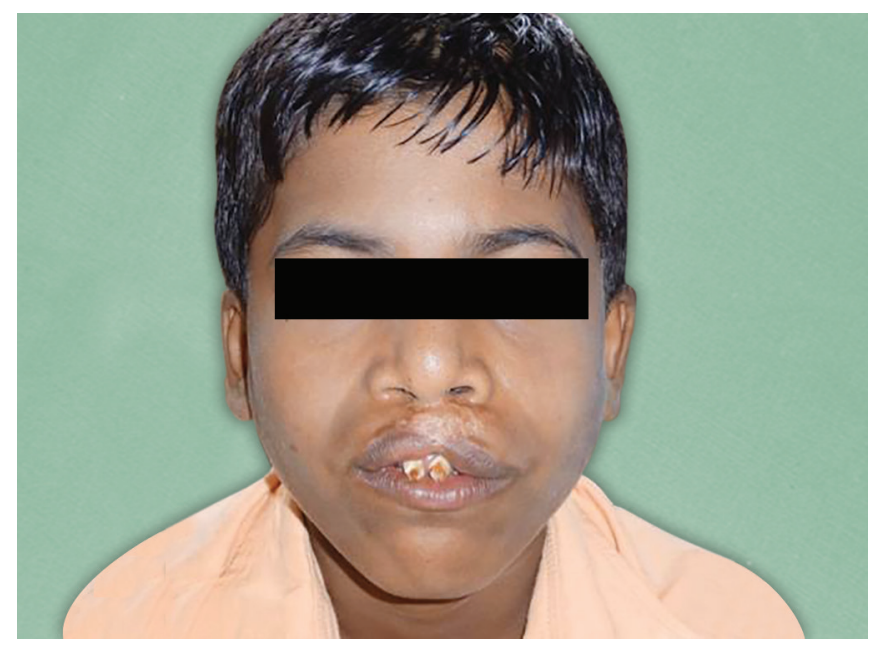

Fig. 11: Presence of extraoral scar

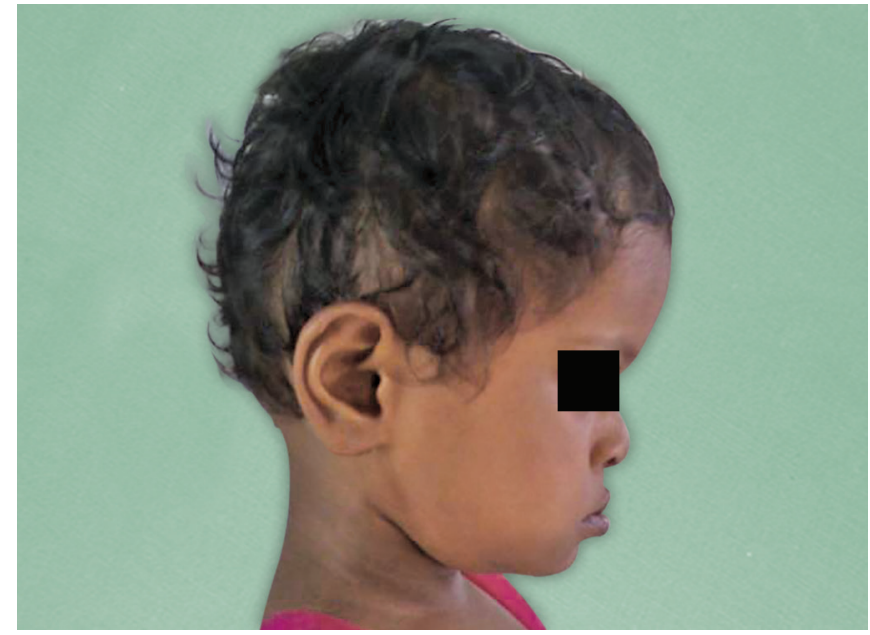

Fig. 13: Presence of midface deficiency

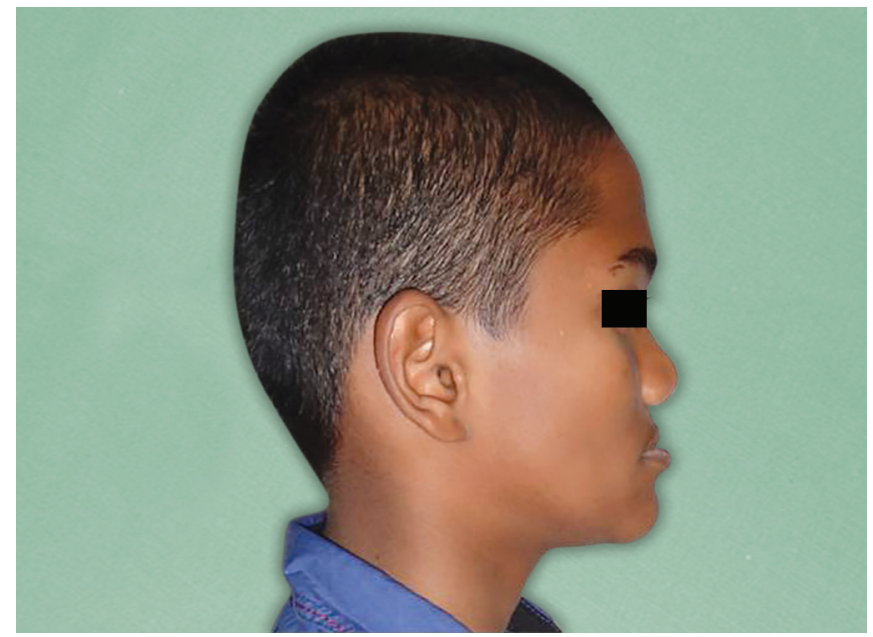

Fig. 15: Patient with a concave profile

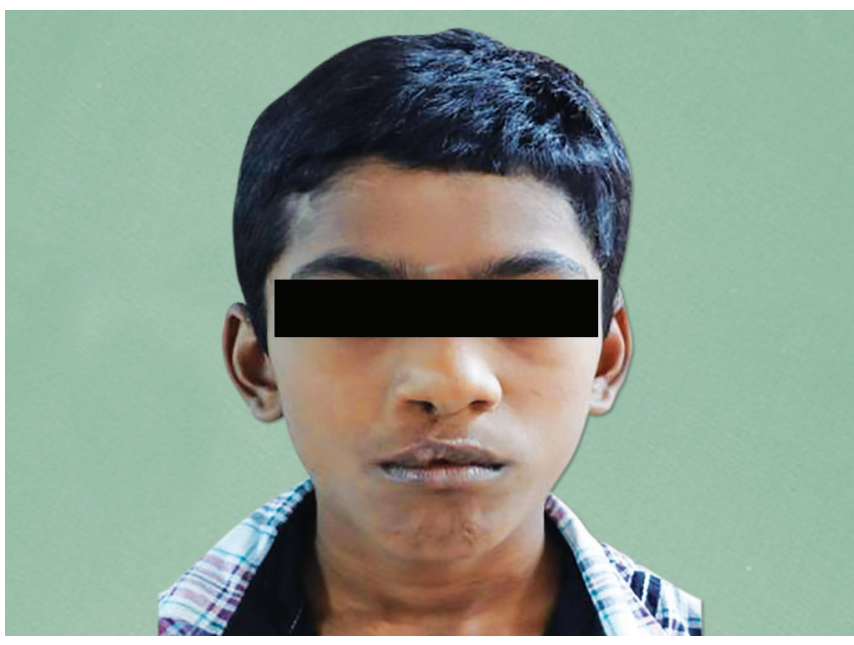

Fig. 12: Columellar deficiency

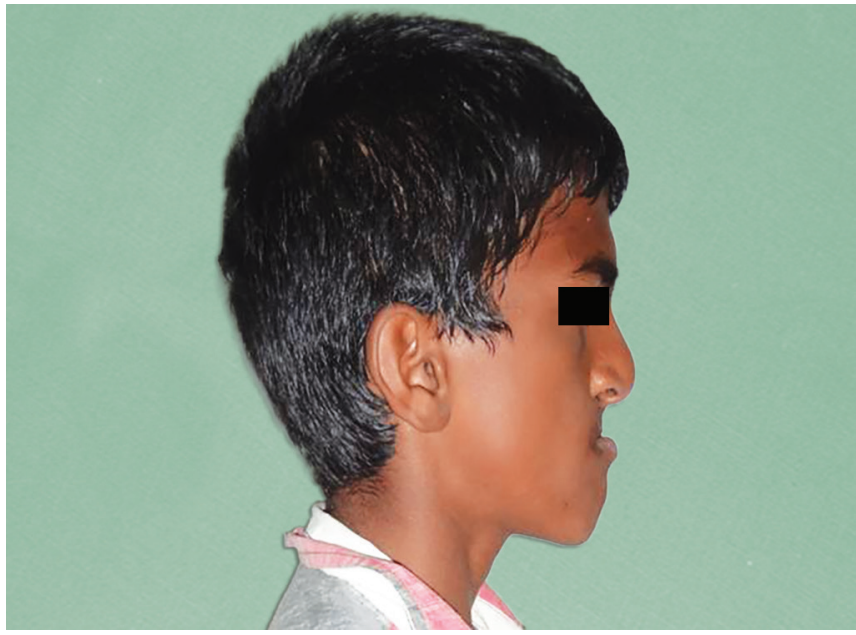

Fig. 14: Presence of mandibular prognathism

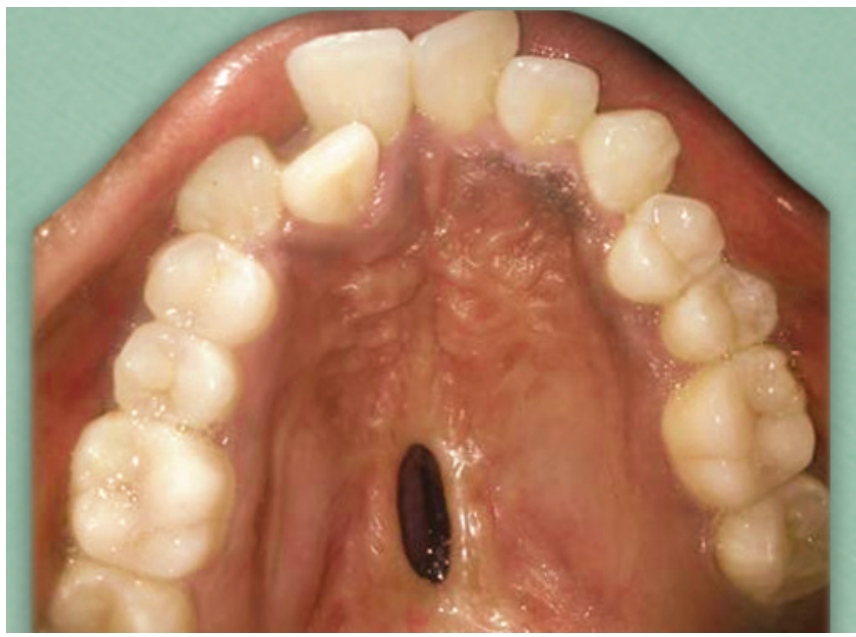

Fig. 16: Presence of residual fistula in hard palate 


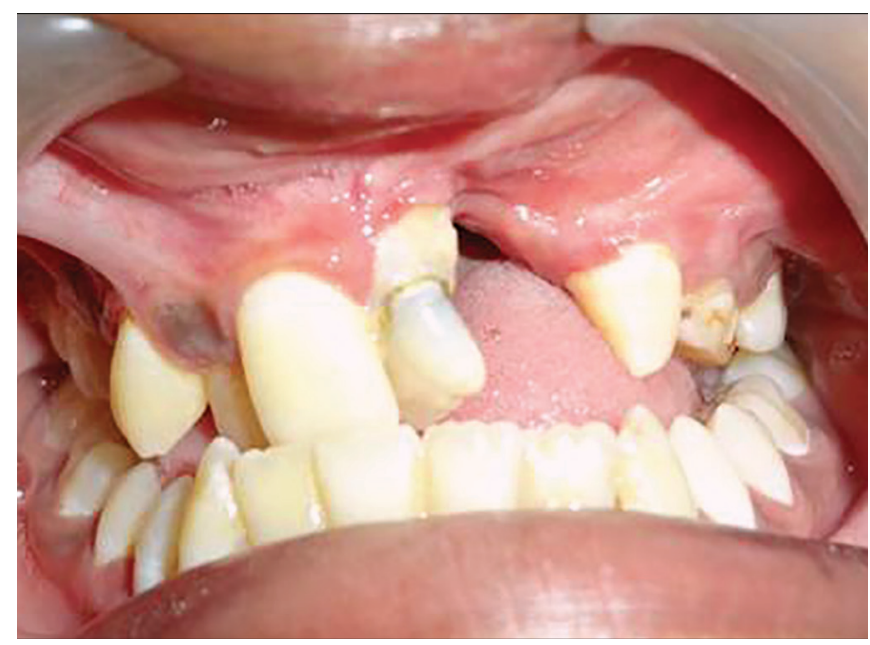

Fig. 17: Presence of complete oronasal residual fistula

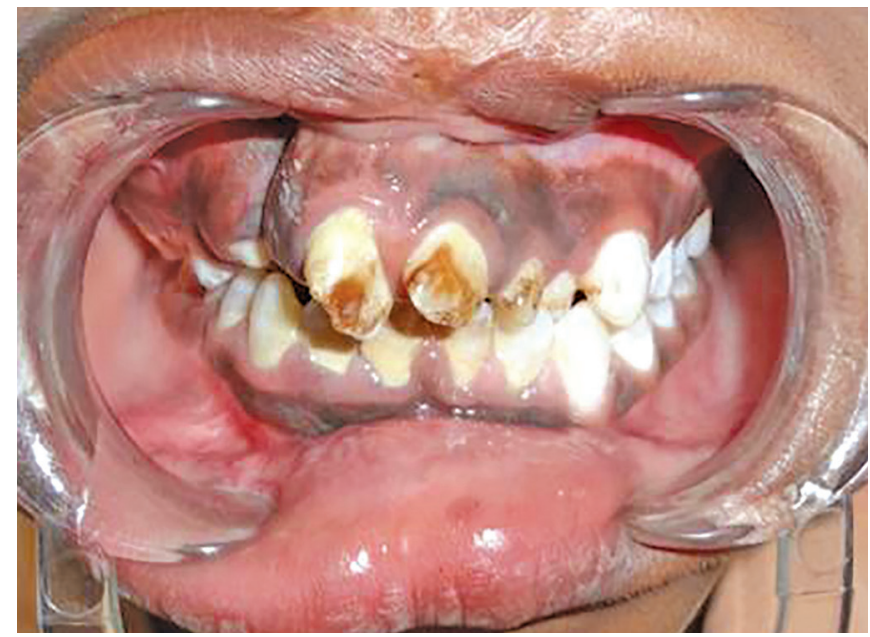

Fig. 19: Protruding premaxilla

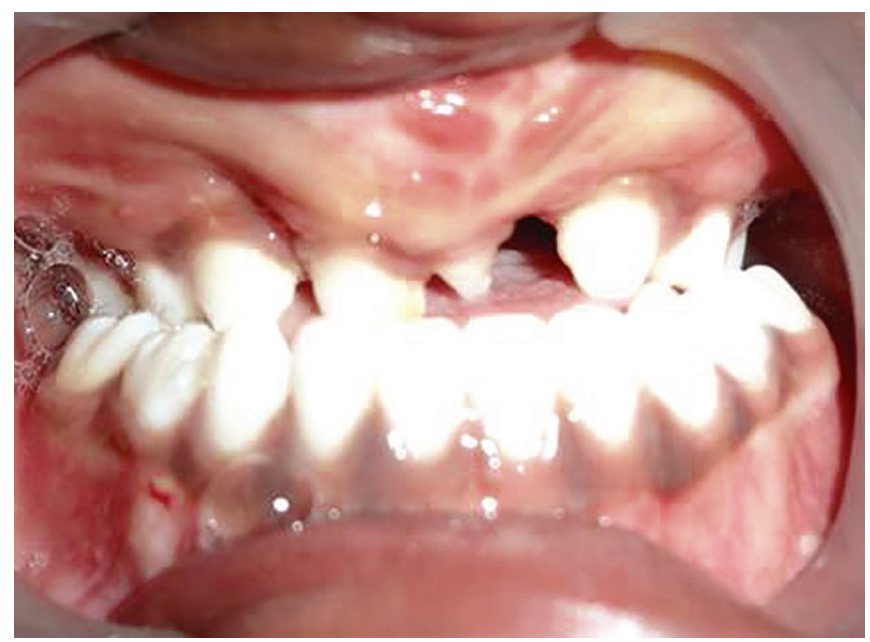

Fig. 21: Anterior cross-bite

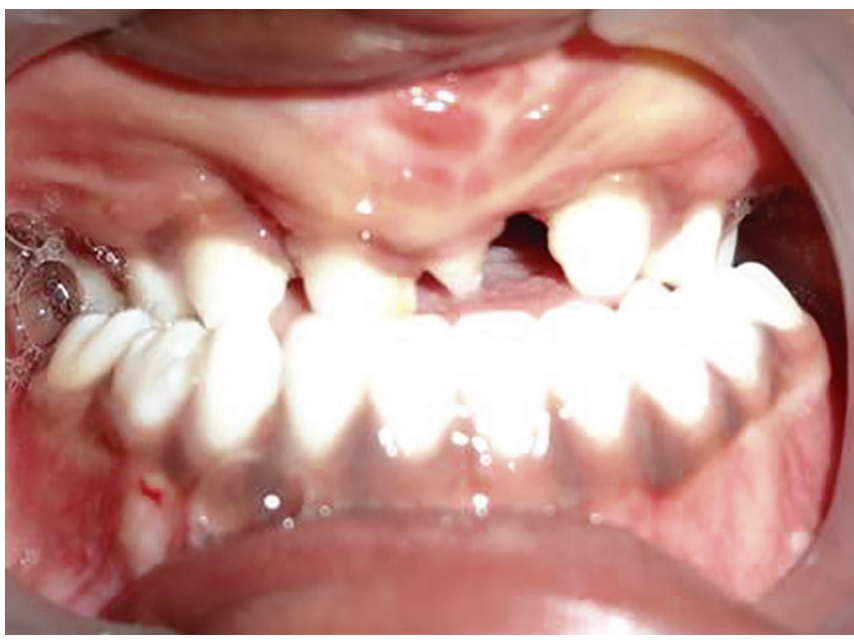

Fig. 18: Cleft in the alveolus

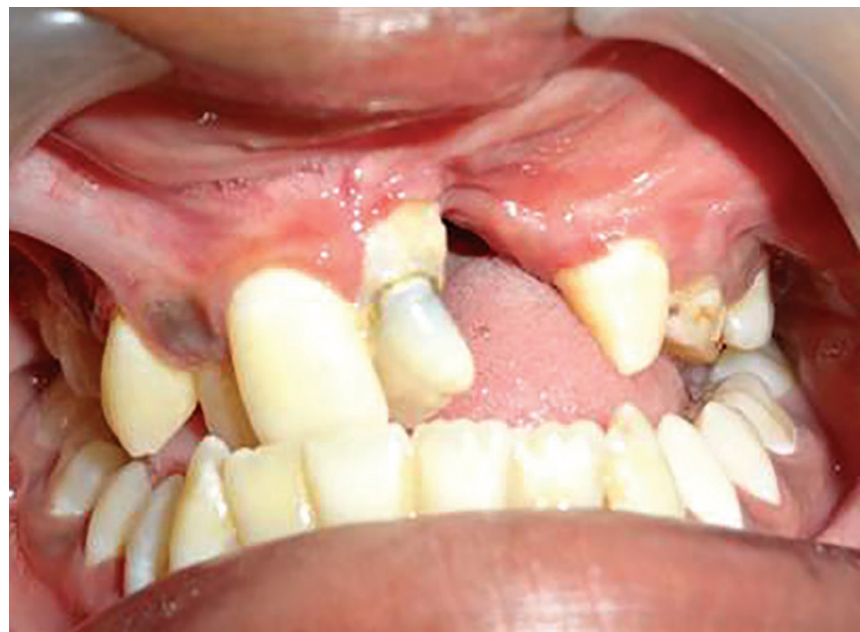

Fig. 20: Mobile premaxillary segments

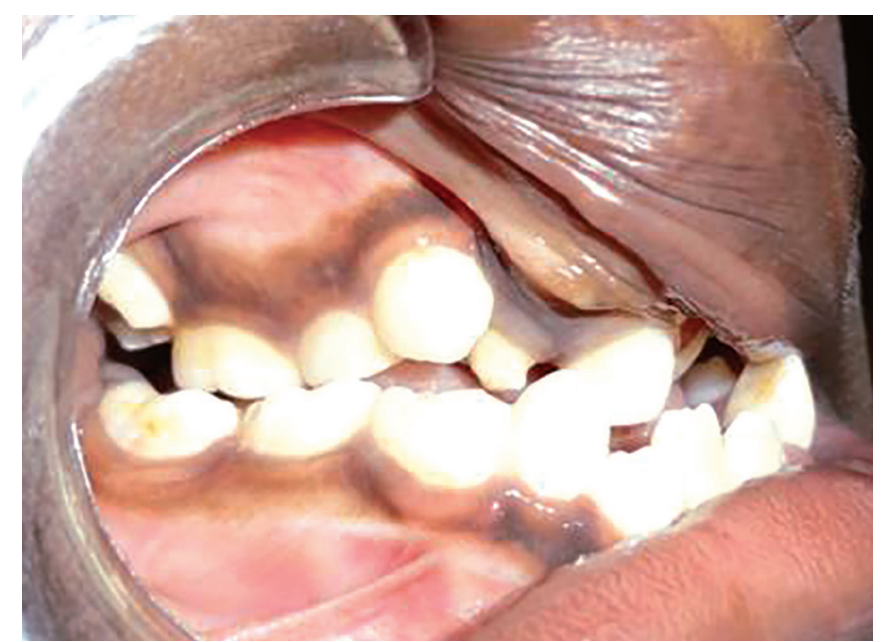

Fig. 22: Posterior unilateral cross-bite 


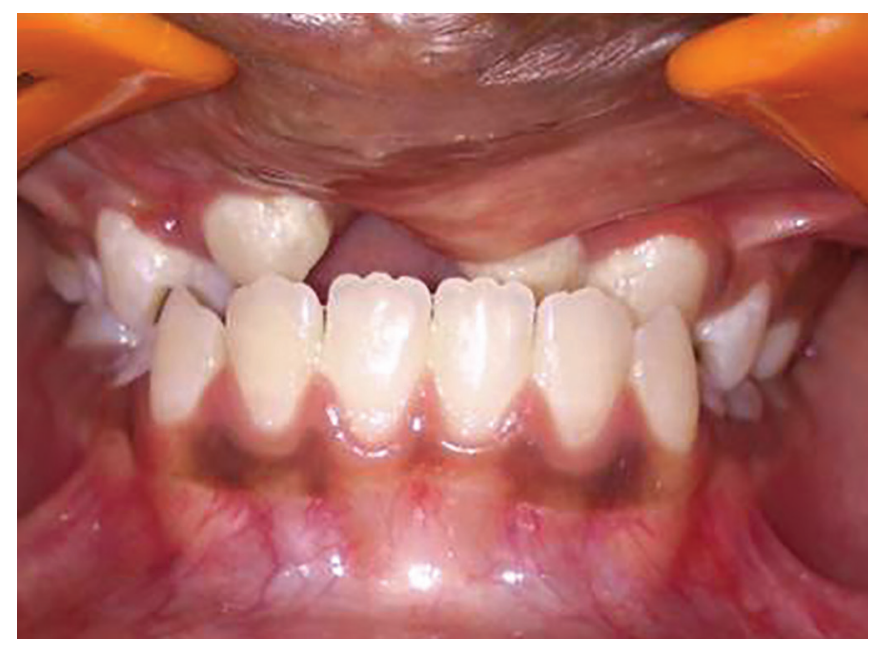

Fig. 23: Posterior bilateral cross-bite

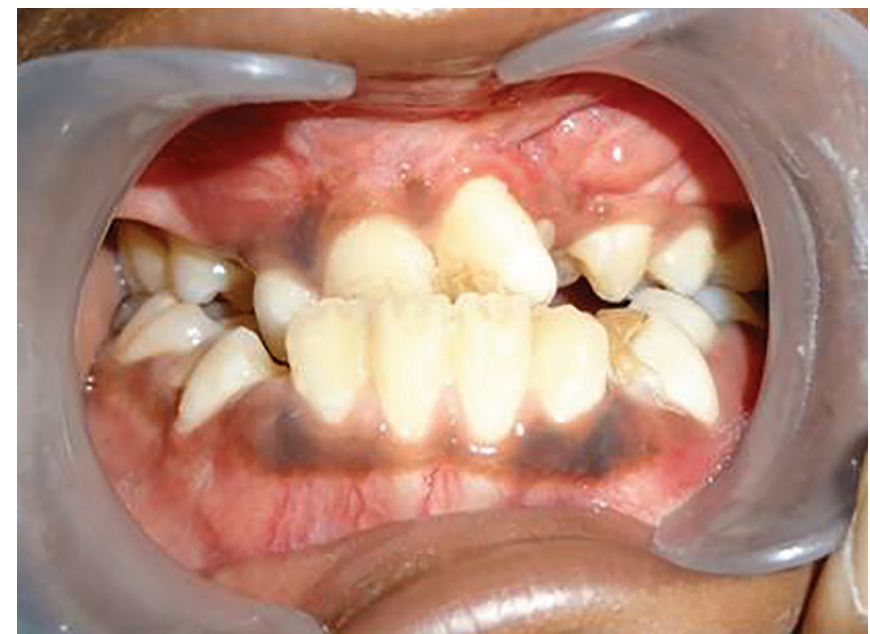

Fig. 25: Congenitally missing tooth

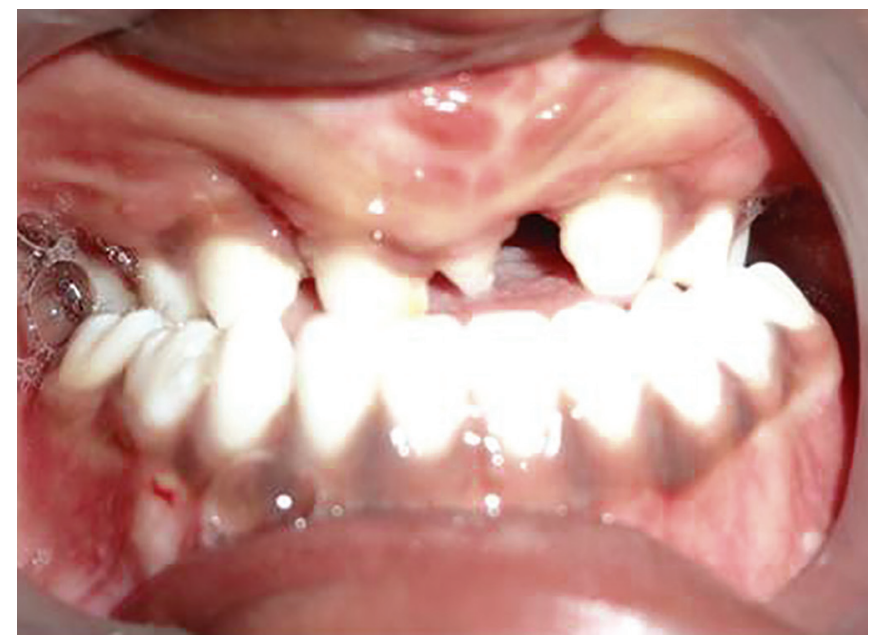

Fig. 27: Supernumerary tooth

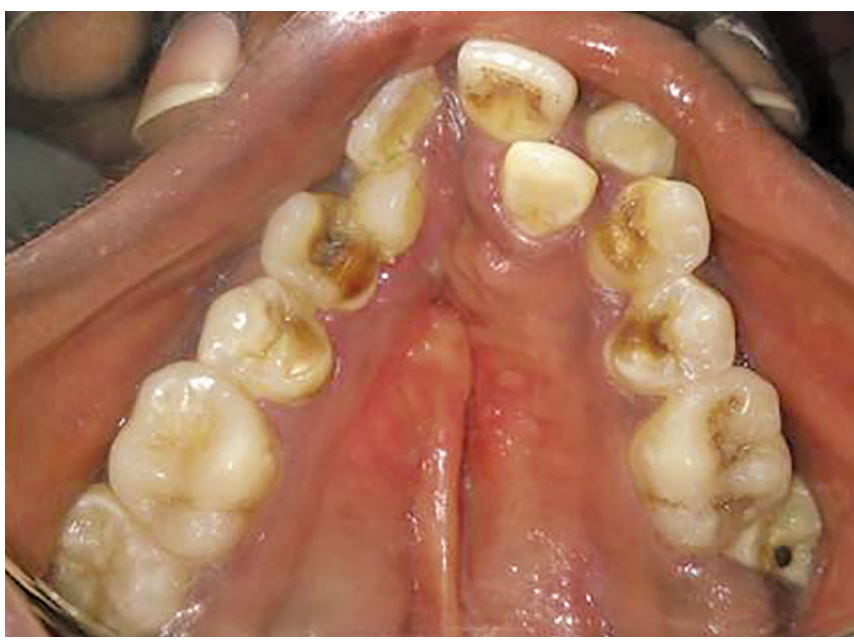

Fig. 24: Constricted upper arch

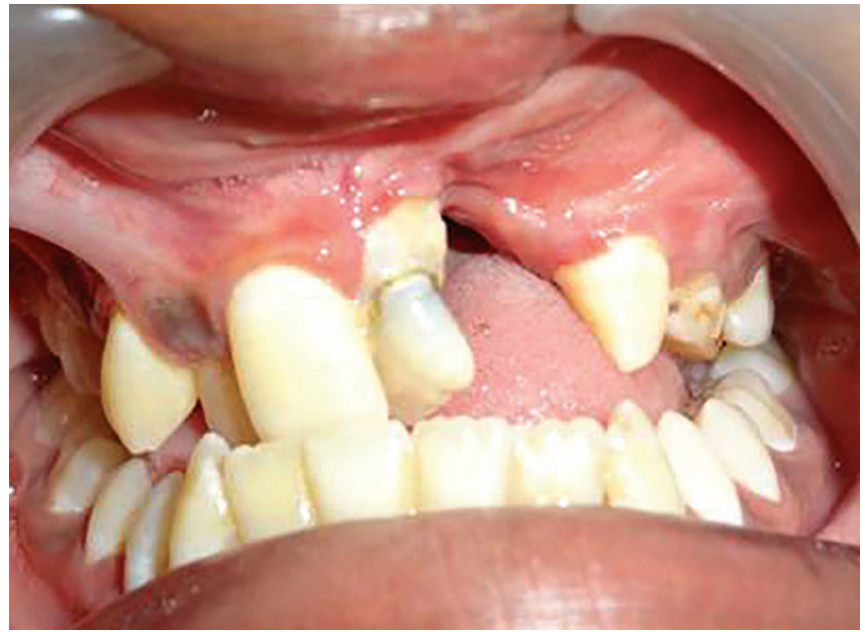

Fig. 26: Ectopically erupted tooth

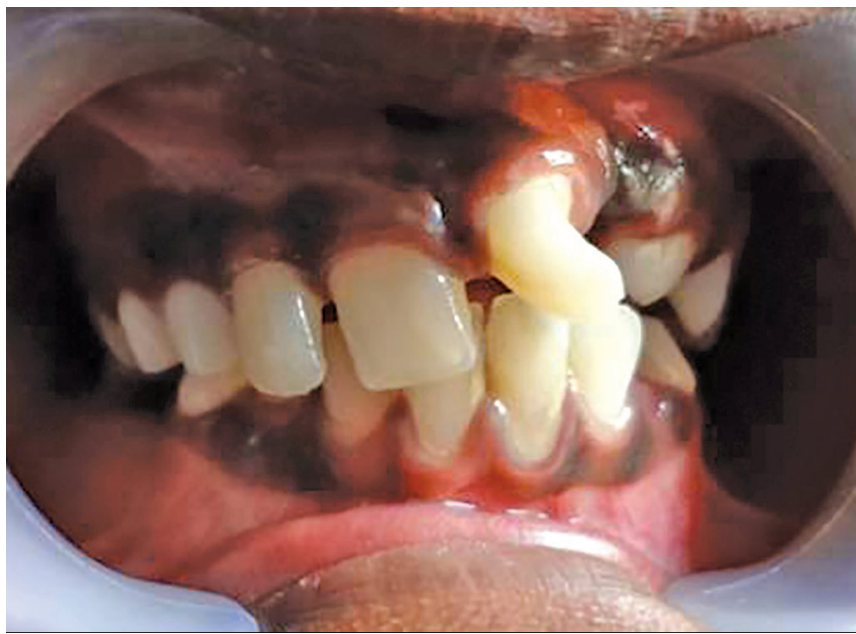

Fig. 28: Aberrations in crown shape 


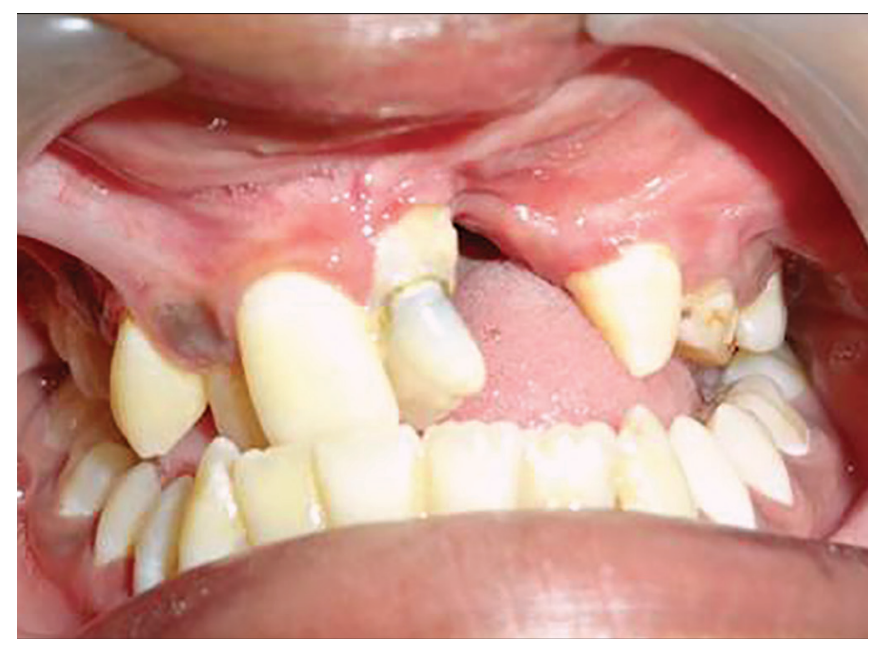

Fig. 29: Peg laterals

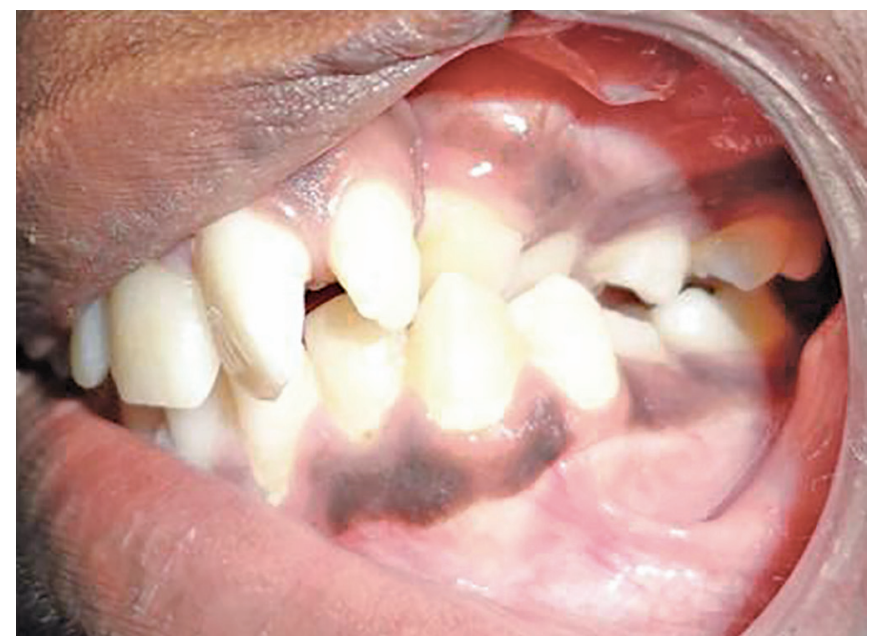

Fig. 31: Macrodontia

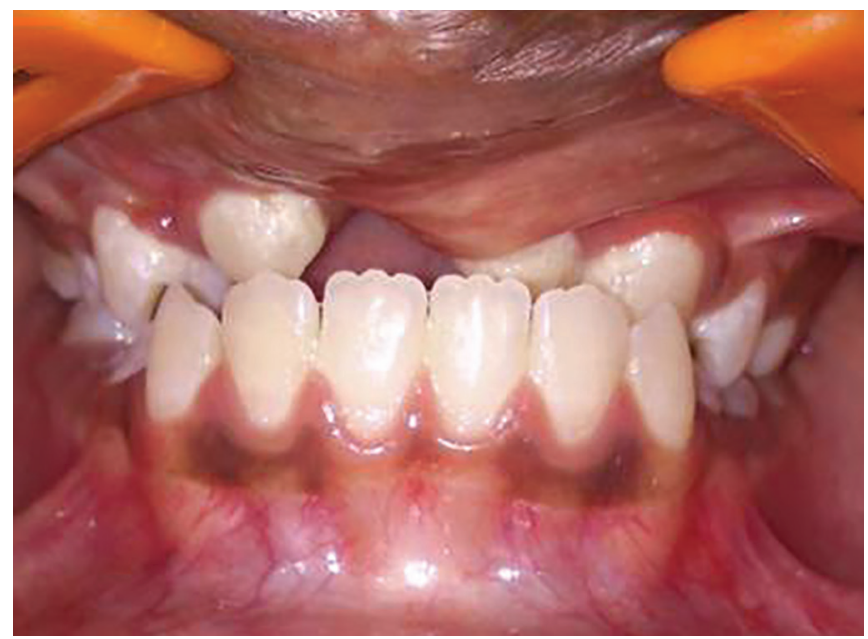

Fig. 33: Hypodontia

\section{Clinical Significance}

The timing of lip repair showed a significant influence on the severity of dentofacial deformities. Lip repair before the age of 1 increases the severity of the deformity.

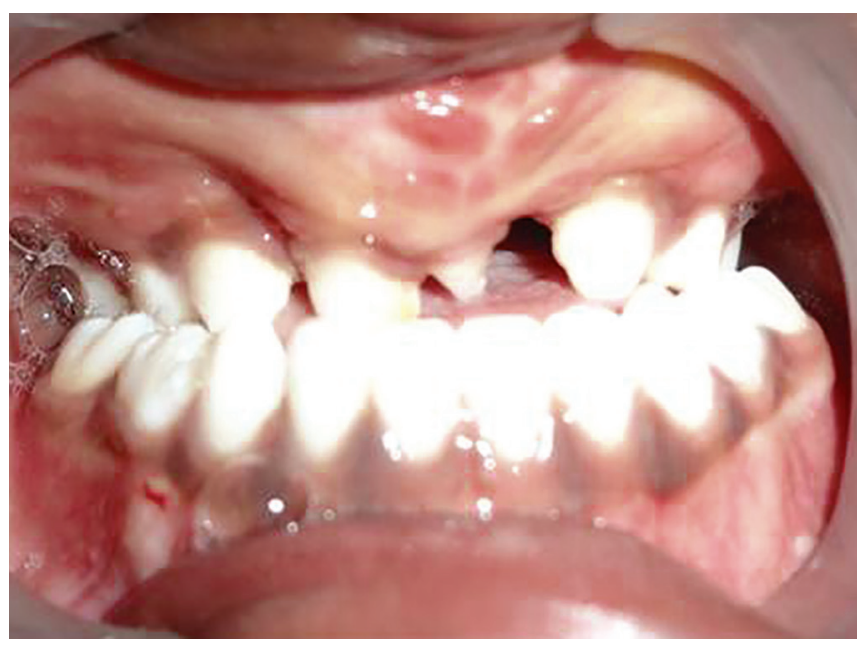

Fig. 30: Microdontia

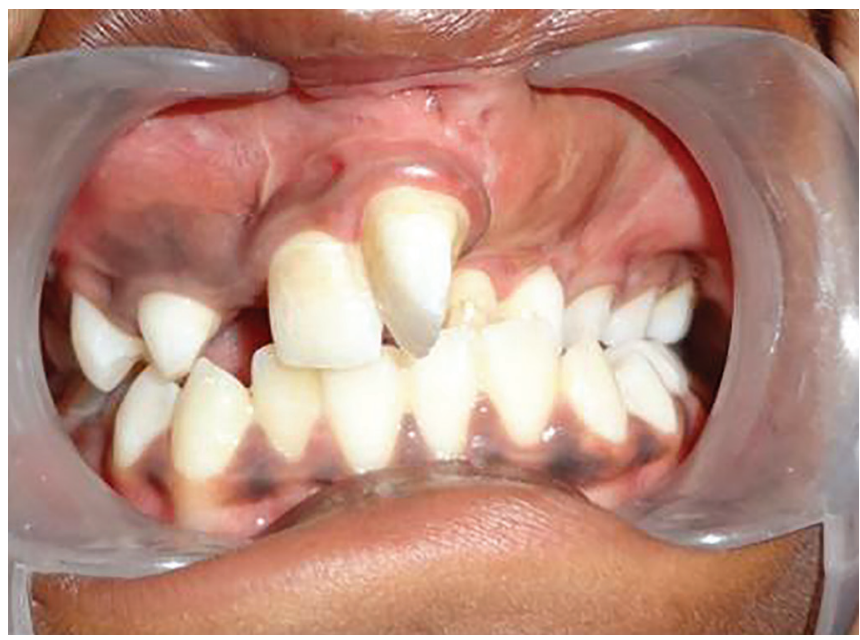

Fig. 32: Rotation of tooth

\section{References}

1. Tolarova MM, Cervenka J. Classification and birth prevalence of orofacial clefts. Am J Med Genet 1998;75:126-137.

2. Canfield MA, Ramadhani TA, et al. Improved national prevalence estimates for 18 selected major birth defects-United States, 1999-2001[reprinted from MMWR Morb Mortal Wkly Rep 2006;54:1301-1305]. JAMA 2006;295:618-620.

3. Enlow DH. Facial growth. AJPA, 3rd ed. Philadelphia: WB Sunders, 1990; pp. 90-92.

4. Dean JA, Avery DR et al. Dentistry for the child and adolescent, Multidisciplinary team approach to cleft lip and palate management, 9th ed., ch. 28; 2011. pp. 614-637.

5. Fraser FC, Fainstat TD. The production of congenital defects in the offspring of pregnant mice treated with cortisone. A progress report. Pediatrics 1991;8:527-533.

6. Fujino H, Tanaka K, et al. Genetic study of cleft lips and cleft palates based upon 2828 Japanese cases. Kyushu J Med Sci 1963;14: 317-331.

7. Newcombe HB. The phenodeviant theory. Fishbein M. Congenital malformations. New York: International Medical Congress, 1963; pp. 345-346.

8. Safra MJ, Oakley GP, et al. Association between cleft lip with or without cleft palate and prenatal exposure to diazepam. Lancet 1975;306:478-480. DOI: 10.1016/S0140-6736(75)90548-6. 
9. Priya VG, Amitha MH. Understanding and management of special child in Pediatric dentistry, 1st ed., 2012; ch. 26, pp. 383-408.

10. Clarren SK, Anderson B, et al. Feeding infants with cleft lip, cleft palate, or cleft lip and palate. Cleft Palate J 1987;24:244-249.

11. Maciel SP, Costa B, et al. Difference in the prevalence of enamel alterations affecting central incisors of children with complete unilateral cleft lip and palate. Cleft Palate Craniofac J 2005;42: 392-395. DOI: 10.1597/02-152.1.

12. Penfold CN. Textbook of Cleft lip and palate-evidence based care: Section 2; 1996.

13. Ziak P, Fedeles Jr J, et al. Timing of primary lip repair in cleft patients according to surgical treatment protocol. Bratis Med J 2010;111:160-162.

14. Guerrero CA. Cleft lip and palate surgery-30 years follow-up. Ann Maxillofac Surg 2012;2:153-157. DOI: 10.4103/2231-0746.101342.

15. Barry HG, Deirdre M. Nasoalveolar molding for infants born with clefts of the lip, alveolus, and palate-clinics in plastic surgery. Semin Plast Surg 2005;19:294-301. DOI: 10.1055/s-2005-925902.

16. Jabber $L$, Halpern $G J$, et al. The impact of consanguinity worldwide. Community Genet 1998;1:12-17. DOI: 10.1159/000016130.

17. Alamoudi NM, Sabbagh HJ, et al. Prevalence and characteristics of non-syndromic orofacial clefts and the influence of consanguinity. J Clin Pediatr Dent 2014;38:241-246. DOI: 10.17796/ jcpd.38.3.bm4m2158v17p2535.

18. Fujino $\mathrm{H}$, Tashiro $\mathrm{H}$, et al. Empirical genetic risk among offspring of cleft lip and cleft palate patients. Jap J Hum Genet 1967;12:62-68.

19. Drillen CM, Ingram CT, et al. The causes and natural history of cleft lip and palate, Edinburgh. E and S Livingstone 1966.

20. Manyama M, Campbell R, et al. An assessment of orofacial clefts in Tanzania. BMC Oral health 2011;2:11-15.

21. Marilyn CJ. Genetics and You. Cleft Palate Foundation, 2nd edn; 2008. www.cleftline.org.

22. Kernahan DA. The Stripped Y-A new classification for cleft lip and palate. Plastic Reconstr Surg 1971;47:469-470. DOI: 10.1097/00006534197105000-00010.

23. Paradowska-Stolarz A, Kawala B. Measurements of mandibular length in patients with total clefts. Dev Period Med 2014;18:110-115.

24. Bichara LM, Araújo RC, et al. Impact of primary palatoplasty on the maxillomandibular sagittal relationship in patients with unilateral cleft lip and palate: a systematic review and meta-analysis. Int J Oral Maxillofac Surg 2015;44:50-56. DOI: 10.1016/j.ijom.2014.08.004.

25. Kremenak CR, Huffman WC, et al. WH. Growth of maxillae in dogs after palatal surgery. I Cleft Palate J 1967;4:6-17.

26. Farronato $G$, Kairyte $L$, et al. How various surgical protocols of the unilateral cleft lip and palate influence the facial growth and possible orthodontic problems? Which is the best timing of lip, palate and alveolus repair?-a literature review. Stomatologija 2014;16:53-60.

27. Bishara SE, Krause JC, et al. Facial and dental relationships of individuals with unoperated clefts of lip and/palate. Cleft Palate J 1976;13:238-252.

28. Pensler JM, Mulliken JB. The cleft lip lower-lip deformity. Plast Reconstr Surg 1988;82:602. DOI: 10.1097/00006534-19881000000007.
29. Mulliken JB. Principles and techniques of bilateral complete cleft lip repair. Plast Reconstr Surg 1985;75:477. DOI: 10.1097/00006534198504000-00003.

30. Lithovius RH, Ylikontiola LP, et al. Incidence of palatal fistula formation after primary palatoplasty in northern Finland. Oral Surg Oral Med Oral Pathol Oral Radiol 2014;118:632-636. DOI: 10.1016/j. oooo.2014.07.002.

31. Hardwicke JT, Landini G, et al. Fistula incidence after primary cleft palate repair: a systematic review of the literature. Plast Reconstr Surg 2014;134:618-627. DOI: 10.1097/PRS.0000000000000548.

32. Galante JM, Costa B, et al. Prevalence of enamel hypoplasia in deciduous canines of patients with complete cleft lip and palate. Cleft Palate Craniofac J 2005;42:675-678. DOI: 10.1597/04-068r.1.

33. Shi B, Losee JE. The impact of cleft lip and palate repair on maxillofacial growth. Int J Oral Sci 2014;14:1038.

34. Paradowska Stolarz A, Kawala B. Occlusal disorders among patients with total clefts of lip, alveolar bone, and palate. Biomed Res Int 2014. DOI: $10.1155 / 2014 / 583416$.

35. Hellquist $\mathrm{R}$, Linder-Aronson $\mathrm{S}$, et al. Dental abnormalities in patients with alveolar clefts, operated upon with or without primary periosteoplasty. Eur J Orthod 1979;1:169-180. DOI: 10.1093/ ejo/1.3.169.

36. Tereza GP, Carrara CF, et al. Tooth abnormalities of number and position in the permanent dentition of patients with complete bilateral cleft lip and palate. Cleft Palate Craniofac J 2010;47:247-252. DOI: 10.1597/08-268.1.

37. Obłoj B The presence of the maxillary lateral incisor in the cleft gap in patients with unilateral cleft lip and palate. Preliminary report. Dev Period Med 2014;18:70-74.

38. Olin WH Dental anomalies in cleft lip and palate patients. Angle Orthodont 1964;34:119-123.

39. Maciel SP, Costa B, et al. Difference in the prevalence of enamel alterations affecting central incisors of children with complete unilateral cleft lip and palate. Cleft Palate Craniofac J 2005;42:392-395. DOI: 10.1597/02-152.1.

40. Oliveira Lima JE, Carvalho Carrara CF, et al. Chronology and sequence of eruption of the permanent teeth in patients with complete unilateral cleft lip and palate. Cleft Palate Craniofac J 2004;41:642645. DOI: 10.1597/02-085.1.

41. Silva F, Strauss RP. Psycological problems and referrals among orofacial team patients. J of Rehabilitation Med 1991;57:31-36.

42. Fishman LS. Factors related to tooth number, eruption time and tooth position in cleft palate individuals. J Dent Child 1970;37:303-306.

43. Saunders DE, Hochberg J, et al. An evaluation of unilateral cleft lip repairs. Presented at the American Society of Plastic \& Reconstructive Surgeons annual meeting, Toronto, Ontario, Oct 21, 1975.

44. Krauss BS, Jordan RE, et al. Dental abnormalities in the primary and permanent dentition of individuals with cleft lip and palate. J Dent Res 1966;45:1736-1746. DOI: 10.1177/00220345660450062601.

45. Trindade IE, de Oliveira Camargo Gomes A, et al. Nasal Airway Dimensions of Children With Repaired Unilateral Cleft Lip and Palate. Cleft Palate Craniofac J 2014;11:14-17. 